\title{
recillunds
}

Revista Científica Mundo de la Investigación y el Conocimiento

Karen Mercedes Barragán Monrroy ${ }^{\text {a; }}$ Holger Bolívar Alvarado Onofre ${ }^{\text {b }}$

Subsistema de áreas naturales protegidas para enfrentar delitos ambientales contra la fauna del cantón Quevedo

Subsystem of protected natural areas to face environmental crimes against the fauna of the Quevedo canton

Revista Científica Mundo de la Investigación y el Conocimiento. Vol. 3 núm.3, septiembre, ISSN: 2588-073X, 2019, pp. 1005-1060

DOI: $10.26820 /$ recimundo/3.(3).septiembre.2019.1005-1060

URL: http://recimundo.com/index.php/es/article/view/558

Código UNESCO: 5605 Legislación y Leyes Nacionales

Tipo de Investigación: Artículo de Revisión

Editorial Saberes del Conocimiento

Recibido: $15 / 05 / 2019$

Aceptado: 23/06/2019

Publicado: 30/09/2019

Correspondencia: karenj1995@hotmail.com

a. Investigador; estudiante de la Facultad de Jurisprudencia de la Universidad Regional Autónoma de los Andes extensión Quevedo; Quevedo Ecuador; karenj1995@ hotmail.com

b. Magister en Gerencia de Innovaciones Educativas; Abogado de los Tribunales y Juzgados de la República del Ecuador; Docente Investigador de la Facultad de Jurisprudencia de la Universidad Regional Autónoma de los Andes extensión Quevedo; Quevedo, Ecuador 


\section{Subsistema de áreas naturales protegidas para enfrentar delitos ambientales contra la fauna del cantón Quevedo}

Vol. 3, núm. 3., (2019)

Karen Mercedes Barragán Monrroy; Holger Bolívar Alvarado Onofre

\section{RESUMEN}

En Ecuador existe un organismo encargado de proteger las áreas verdes el cual se llama Sistema Nacional de Áreas Protegidas. Su función es determinar aquellas regiones donde su biodiversidad todavía sea vulnerable a los cambios e impactos generados por la mano del hombre. La provincia de Los Ríos tiene un área natural denominada Humedal Abras de Mantequilla donde existe una gran variedad de aves y fauna característica de esa región. Este humedal pertenece a los cantones Vinces, Babahoyo y Pueblo Viejo. En el cantón Quevedo no existe un área que está registrada en los sistemas gubernamentales encargados del medio ambiente ecuatoriano, pero no se excluye que posea dentro de sus límites geográficos una flora y fauna importante. El objetivo general de esta investigación es analizar los subsistemas de áreas naturales protegidas para enfrentar delitos ambientales contra la fauna del cantón Quevedo. La metodología aplicada se basó en una investigación de tipo cuali-cuantitativa. Los resultados se basaron en el análisis de las áreas naturales protegidas del ecuador, así como también la biodiversidad, ecosistemas y delitos ambientales de la provincia de Los Ríos, sin olvidar la normativa legal de la protección de la fauna silvestre en el Ecuador. Como conclusión se obtuvo que los delitos ambientales que pueden estar en contra de la fauna es el tráfico de mamíferos, reptiles y aves, a través de datos que provienen de los animales decomisados vivos y como carne de monte; el cantón Quevedo no escapa de estas estadísticas ya que muchos de estos animales, que estaban en cautiverio, son utilizados como mascotas domésticas y como alimento en las mesas de los cantoneses, generando un gran impacto ambiental en la zona, pero sobre todo un impacto en el animal debido al cambio de su habitad; por lo tanto, para evitar esta falta al medio ambiente existen los derechos, sobre los ecosistemas y biodiversidad presentes en las áreas naturales, dentro de la Constitución de la República del Ecuador y Tratados Internacionales acogidos por la legislación ecuatoriana.

Palabras Claves: Ecosistema; Biodiversidad; Áreas Naturales Protegidas; Delito Ambiental. 


\title{
Subsistema de áreas naturales protegidas para enfrentar delitos ambientales contra la fauna del cantón Quevedo
}

Vol. 3, núm. 3., (2019)

Karen Mercedes Barragán Monrroy; Holger Bolívar Alvarado Onofre

\begin{abstract}
In Ecuador there is an agency responsible for protecting green areas which is called the National System of Protected Areas. Its function is to determine those regions where its biodiversity is still vulnerable to the changes and impacts generated by the hand of man. Los Ríos province has a natural area called Abras de Mantequilla Wetland where there is a great variety of birds and fauna characteristic of that region. This wetland belongs to the cantons Vinces, Babahoyo and Pueblo Viejo. In the Quevedo canton there is no area that is registered in the government systems responsible for the Ecuadorian environment, but it is not excluded that it has important flora and fauna within its geographical boundaries. The general objective of this research is to analyze the subsystems of protected natural areas to face environmental crimes against the fauna of the Quevedo canton. The methodology applied was based on a qualitative-quantitative investigation. The results were based on the analysis of the protected natural areas of Ecuador, as well as the biodiversity, ecosystems and environmental crimes of the province of Los Ríos, without forgetting the regulations legal protection of wildlife in Ecuador. In conclusion, it was obtained that the environmental crimes that may be against the fauna is the traffic of mammals, reptiles and birds, through data that come from live confiscated animals and as bushmeat; The canton Quevedo does not escape these statistics since many of these animals, which were in captivity, are used as domestic pets and as food on the tables of the Cantonese, generating a great environmental impact in the area, but above all an impact on the animal due to the change of its habitat; therefore, to avoid this lack of the environment there are rights, on the ecosystems and biodiversity present in natural areas, within the Constitution of the Republic of Ecuador and International Treaties accepted by the Ecuadorian legislation
\end{abstract}

Key Words: Ecosystem; Biodiversity; Protected Natural Areas; Environmental Crime. 


\section{Subsistema de áreas naturales protegidas para enfrentar delitos ambientales contra la fauna del cantón Quevedo}

Vol. 3, núm. 3., (2019)

Karen Mercedes Barragán Monrroy; Holger Bolívar Alvarado Onofre

\section{Introducción.}

El desarrollo de las sociedades fue a través de buscar soluciones a las necesidades inherentes de los individuos que las conformaban. Para poder cubrir estos compromisos, los sujetos tuvieron que desarrollar habilidades que le permitieran obtener los recursos. Las primeras

actividades fueron la caza y pesca lo cual derivó a que se desplazaran de un territorio a otro consiguiendo el subsistir. Con esto empezó el contacto humano con otras especies de vida y otros ecosistemas.

Este contacto a generado u impacto creciente a medida que evoluciona las comunidades. El desarrollo de soluciones que permiten una mejor calidad de vida ha hecho también meya en los ecosistemas y la biodiversidad. De aquí, nace la preocupación de como seguir preservando esos territorios ricos en diversos factores ambientales como agua, suelo, aire, flora y fauna.

El problema que vive actualmente la biodiversidad es de carácter global y debe abarcarse en conjunto con otras áreas de la ciencia para buscar las soluciones al creciente contacto del hombre con las áreas naturales, como se detalla en la Figura 1. Ya estos estudios no pueden ser tomados por parte de aquellos que solo estudian la biología, sino que debe ser atendido por múltiples profesionales que busquen un mínimo acuerdo de conservación del habitad natural. 


\section{Subsistema de áreas naturales protegidas para enfrentar delitos ambientales \\ contra la fauna del cantón Quevedo}

Vol. 3, núm. 3., (2019)

Karen Mercedes Barragán Monrroy; Holger Bolívar Alvarado Onofre

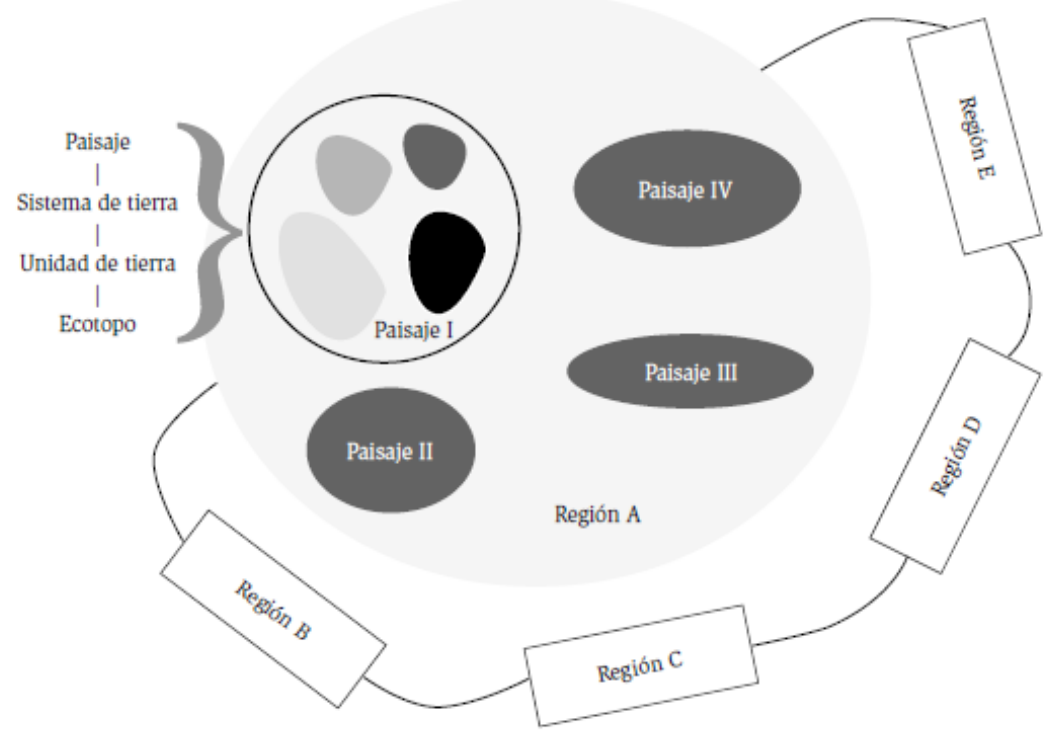

Figura 1. En el espacio real, los componentes físicos y bióticos se integran en ensambles o unidades, las cuales por agregación conforman un sistema jerárquico o transescalar que incluye paisajes y regiones. Fuente: (Toledo, 2005)

"La biodiversidad (los conjuntos de organismos) por más que se les aísle y circunscriba no existen más como "naturaleza prístina", pues la expansión de la especie humana ha terminado por articular como nunca antes en la historia, los procesos del mundo natural con los del social. Dicho de otra manera, en el mundo globalizado contemporáneo, la conservación de la biodiversidad es imposible sin tomar en cuenta el conjunto de factores sociales que la condicionan”.(Toledo, 2005, pág. 70)

El cuidado de la biodiversidad depende de factores subjetivos como la percepción ambiental que tenga la sociedad. Estas percepciones son fundamentales y como medios 


\section{Subsistema de áreas naturales protegidas para enfrentar delitos ambientales contra la fauna del cantón Quevedo}

Vol. 3, núm. 3., (2019)

Karen Mercedes Barragán Monrroy; Holger Bolívar Alvarado Onofre

principales se incluyen los mismos órganos sensitivos del hombre, tacto, vista y olor. Involucrar

al individuo en esta corriente es fundamental ya que principalmente es el que hace vida alrededor

de estos ecosistemas. Las percepciones ambientales han sido abordadas por disciplinas como la psicología, la antropología y la geografía, donde ésta última ha contribuido a desarrollar una visión integradora que contempla el proceso de toma de decisiones en torno al ambiente y su manejo(Fernández Moreno, 2008).

Los sentidos y las percepciones de cómo deben protegerse esta biodiversidad debe llevarse a los principales entes gubernamentales para que dicha protección deba convertirse en ley. El manejo de los recursos requiere ser continuamente debatido a partir de las propuestas de los diferentes actores, de sus conocimientos, objetivos perseguidos, valores y experiencias, con el fin de construir plataformas de negociación social y política que permitan acceder a él(Paz Salinas, 2008).

Es importante, el estudio y análisis de los factores que puedan disminuir la calidad de vida de los ecosistemas. Cuando los hogares llevan a cabo el acto de apropiación tienen diferentes formas de interactuar con el ecosistema, cada una de las cuales impacta o afecta de manera diferente a los ecosistemas y paisajes, generando una expresión territorial y espacial(García-Frapolli \& Toledo, 2008).Es decir, deben existir los mecanismos diversos, tanto personales como jurídicos para poder contrarrestar el impacto ambiental.

No solo el impacto ambiental es ocurrido por la mano del hombre, sino que también es producto de las catástrofes ambientales producto del cambio climático. Las evaluaciones de cambios climáticos muestran que pueden existir áreas sensibles, con efectos negativos de 


\section{Subsistema de áreas naturales protegidas para enfrentar delitos ambientales contra la fauna del cantón Quevedo}

Vol. 3, núm. 3., (2019)

Karen Mercedes Barragán Monrroy; Holger Bolívar Alvarado Onofre degradación de fuentes de agua potable, limitación de la producción alimentaria, tensiones económicasy riesgos crecientes de inundación en zonas costeras o bajas(Bacusoy, Díaz, \& Gavilánez, 2019).

Indistintamente, sea cual sea el factor catalizador de los impactos ambientales es un compromiso realizar una investigación científica que arroje resultados que busquen minimizar el contacto indiscriminado del hombre con su habitad. Es necesario la realización de un seguimiento ambiental y la ejecución de técnicas idóneas para la remediación y recuperación del área afectada, y de esta forma, se puedan prever y atenuar futuros impactos negativos que se puedan provocar(Moreno, Salazar, Aveiga, \& Peñaherrera, 2018).

De toda esta causa en contra de la biodiversidad y el ecosistema, las políticas que se impulsan a través de la evaluación del impacto ambiental del hombre hacia su entorno y habitad, también es necesario poder establecer normativas de restricción de áreas naturales que sean importante para el desarrollo de la humanidad. Se deben crear áreas naturales protegidas.

"Las primeras áreas silvestres protegidas del mundo fueron creadas durante el siglo pasado con el fin de proteger paisajes considerados con especial valor escénico. En algunos casos, la declaración de ciertas áreas como reservas naturales también estuvo motivada en la necesidad de proteger cuencas hidrográficas consideradas estratégicas. La mayoría de las reservas correspondían a terrenos de bajo interés económico, ya fuera por su localización o por el tipo y calidad de los recursos contenidos. Sólo de manera secundaria $-\mathrm{y}$ muchas veces fortuita - las primeras reservas naturales cumplían además con una función de 


\section{Subsistema de áreas naturales protegidas para enfrentar delitos ambientales contra la fauna del cantón Quevedo}

Vol. 3, núm. 3., (2019)

Karen Mercedes Barragán Monrroy; Holger Bolívar Alvarado Onofre

conservación biológica, a través de proteger ciertas especies de fauna conspicuas”.(Sepúlveda, Moreira, \& Villarroel, 1997, pág. 48)

La creación de estas áreas naturales protegidas tiene como uno de sus objetivos evitar la fragmentación de la biodiversidad, como ha ocurrido al comienzo de la formación de las sociedades. Así, territorios que antes presentaban un paisaje natural continuo comienzan a cambiar su estructura por una de parches discontinuos de hábitat, cambiando con ello la composición de las especies y los procesos ecológicos básicos(Sepúlveda, Moreira, \& Villarroel, 1997). Esto se puede visualizar en la Figura 2.

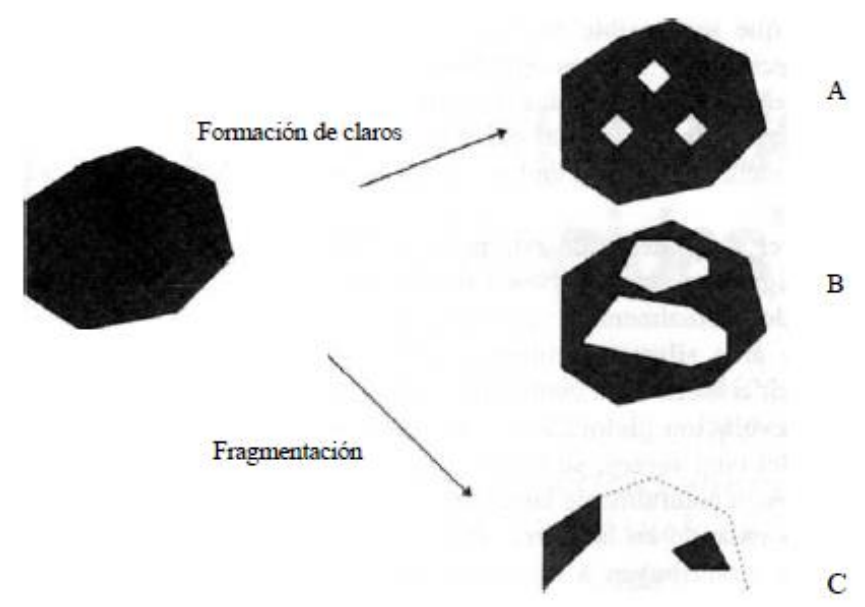

Figura 2. Fragmentación del habitad de un bosque. En el caso A, se inicia la apertura de claros o «perforación» del paisaje. En B, los claros se toman mayores y más numerosos, hasta que finalmente en $\mathrm{C}$, la matriz de paisaje cambia desde bosque a un hábitat 


\section{Subsistema de áreas naturales protegidas para enfrentar delitos ambientales contra la fauna del cantón Quevedo}

Vol. 3, núm. 3., (2019)

Karen Mercedes Barragán Monrroy; Holger Bolívar Alvarado Onofre

antropogénico. Fuente: (Sepúlveda, Moreira, \&

Villarroel, 1997)

Se forma una nueva percepción ambiental entre las comunidades que tienen contacto con el ecosistema. Esta nueva visión es que crean a las áreas naturales protegidas como patrimonio natural y cultural de la sociedad. Estas áreas son poseedoras de especies, paisajes, rasgos antropológicos, arqueológicos, paleontológicoso culturales de singular valor(Goicochea, 2011).El objetivo es preservar los ambientes naturales representativos de las regiones, así como la diversidad genética de las especies silvestres, en particular las que están en peligro de extinción, las amenazadas, las endémicas y las que se encuentran sujetas a protección especial(Vázquez Torres, Carvajal Hernández, \& Aquino Zapata, 2010).

Estas áreas naturales protegidas son un conjunto de mecanismos estatales que a través de los entes estadales, regionales y municipales pretenden amparar la biodiversidad del planeta. Las primeras protegidas son los parques nacionales, aunque también destaca la creación delas zonas protectoras forestales y la protección de puntos importantes del territorio nacional(Villalobos, 2000). En la Tabla 1 se detalla cómo están formados las áreas naturales protegidas en función de la geografía del país.

Tabla 1. 


\section{Subsistema de áreas naturales protegidas para enfrentar delitos ambientales contra la fauna del cantón Quevedo}

Vol. 3, núm. 3., (2019)

Karen Mercedes Barragán Monrroy; Holger Bolívar Alvarado Onofre

Categorías de las áreas naturales protegidas en diferentes órdenes de gobierno.

\begin{tabular}{lll}
\hline Estadales & Regionales & Municipales \\
\hline Reservas de la biosfera & Reservas ecológicas & $\begin{array}{l}\text { Parques ecológicos, escenarios } \\
\text { y urbanos }\end{array}$ \\
\hline Parques Nacionales & Parques Estatales & $\begin{array}{l}\text { Zonas de valor escénico y/o } \\
\text { recreativo }\end{array}$ \\
\hline $\begin{array}{l}\text { Monumentos naturales } \\
\text { Áreas de protección de } \\
\text { recursos naturales }\end{array}$ & $\begin{array}{l}\text { Zonas de restauración } \\
\text { multifuncionales y riparios }\end{array}$ & \\
\hline $\begin{array}{l}\text { Áreas de protección de flora y } \\
\text { fauna; Santuarios }\end{array}$ & $\begin{array}{l}\text { Jardines de regeneración o } \\
\text { conservación de especies }\end{array}$ & \\
\hline $\begin{array}{l}\text { Parques y Reservas Estatales } \\
\text { Zonas de preservación } \\
\text { ecológica de los centros de } \\
\text { población }\end{array}$ & & \\
\hline
\end{tabular}

Fuente: (Vázquez Torres, Carvajal Hernández, \& Aquino Zapata, 2010)

En el Ecuador presenta una de los ecosistemas con mayor biodiversidad de Suramérica.

Ocupa el séptimo lugar entre 17 países más ricos en biodiversidad y posee más de 18.189 especies de plantas vasculares, de las cuales más de 5.000son endémicas, convirtiéndolo en uno de los países con más diversidad vegetal por unidad de superficie (Villareal, 2015). El mapa de las diversas superficies del Ecuador continental se puede observar en la Figura 3. 


\section{Subsistema de áreas naturales protegidas para enfrentar delitos ambientales}

contra la fauna del cantón Quevedo

Vol. 3, núm. 3., (2019)

Karen Mercedes Barragán Monrroy; Holger Bolívar Alvarado Onofre

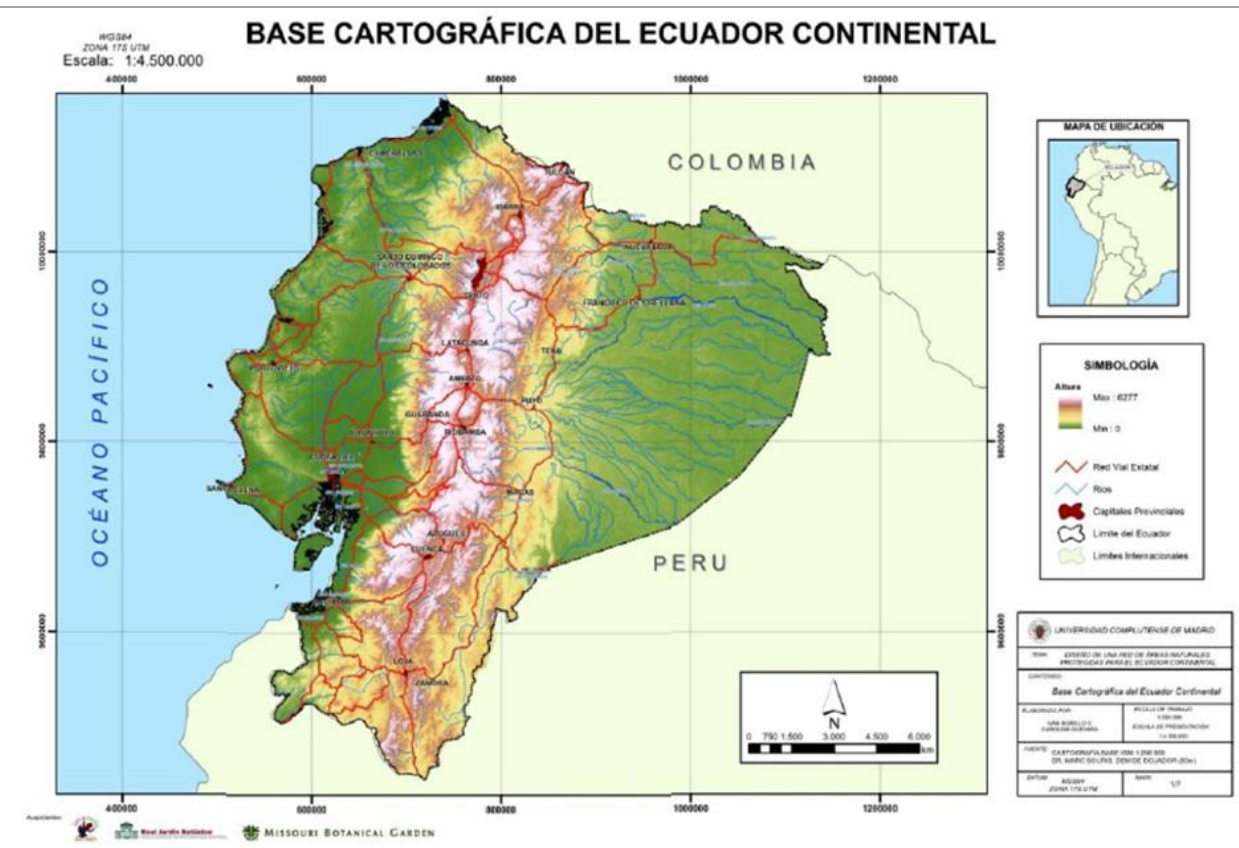

Figura 3. Mapa de las diversas superficies del Ecuador continental. Fuente: (Villareal, 2015)

"En Ecuador, la primera reserva natural en ser creada fue el Parque Nacional Galápagos en 1959 con motivo del centenario de la publicación del libro El Origen de las Especies de Charles Darwin, quien visitó las islas en 1830 donde se inspiró para desarrollar la Teoría del Origen de las Especies. Debido a su fauna particular,Galápagos fue declarado en 1978 PatrimonioNatural de la Humanidad por la UNESCO y en1985, reserva de la biósfera. En1989 se crea la Reserva Marina Galápagos (únicareserva marina del Sistema Nacional de Áreas Protegidas). Actualmente, elParque Nacional Galápagos cuenta con una extensiónde $7.995 \mathrm{~km}^{2}$.La primera reserva natural en la parte continentaldel Ecuador fue el Parque Nacional Cotopaxifundado en agosto de 1975. Posee cerca de32.255 Ha”.(Zambrano, 2015, pág. 43) 


\section{Subsistema de áreas naturales protegidas para enfrentar delitos ambientales contra la fauna del cantón Quevedo}

Vol. 3, núm. 3., (2019)

Karen Mercedes Barragán Monrroy; Holger Bolívar Alvarado Onofre

Existen otras áreas forestales que son vulnerables al apetito voraz que tienen las sociedades por desarrollar sus tecnologías en busca de satisfacer algo más allá de las necesidades básicas. Las áreas naturales protegidas en el Ecuador enfrentan situaciones críticas tanto en sumanejo administrativo, en el control del uso delos recursos por las poblaciones aledañas, como por la presencia de actividades extractivas de recursos naturales no renovables(Mendoza, 2009).

El impacto ambiental que se ha generado la explotación de hidrocarburos en la zona amazónica del Ecuador ha sido bastante grande debido al derrame de miles de barriles de crudo en este pulmón ecuatoriano. Además, la actividad extractiva petrolera necesitó la construcción de vías de acceso e implantación de infraestructura, lo que produjo deforestación, extinción de especies, rotura del ecosistema y daño ecológico general en todos los escenarios intervenidos(De Santis, 2018)

Ecuador no escapa a los desbastadores problemas del cambio climático. Aunado a los desastres ambientales creados por el hombre, la biodiversidad ecuatoriana está sufriendo las consecuencias de una deliberada inconciencia del colectivo en todas sus aristas. En los últimos años se ha evidenciado una vulnerabilidad debido a que un porcentaje importante de su economía y fuerza laboral depende de actividades primarias sensibles al clima, tales como la agricultura, la pesca y el uso de sus recursos naturales(Yánez, Núñez, Carrera, \& Martínez, 2011).

Pero el estado ecuatoriano ha empezado a cambiar su perspectiva de respeto al medio ambiente y su biodiversidad a través de mecanismos políticos enmarcados en las diferentes leyes y normas que brindan la jurisprudencia de la nación, por supuesto empezando por la carta magna. Esto se puede ver a través de la Figura 4. 


\section{Subsistema de áreas naturales protegidas para enfrentar delitos ambientales contra la fauna del cantón Quevedo}

Vol. 3, núm. 3., (2019)

Karen Mercedes Barragán Monrroy; Holger Bolívar Alvarado Onofre

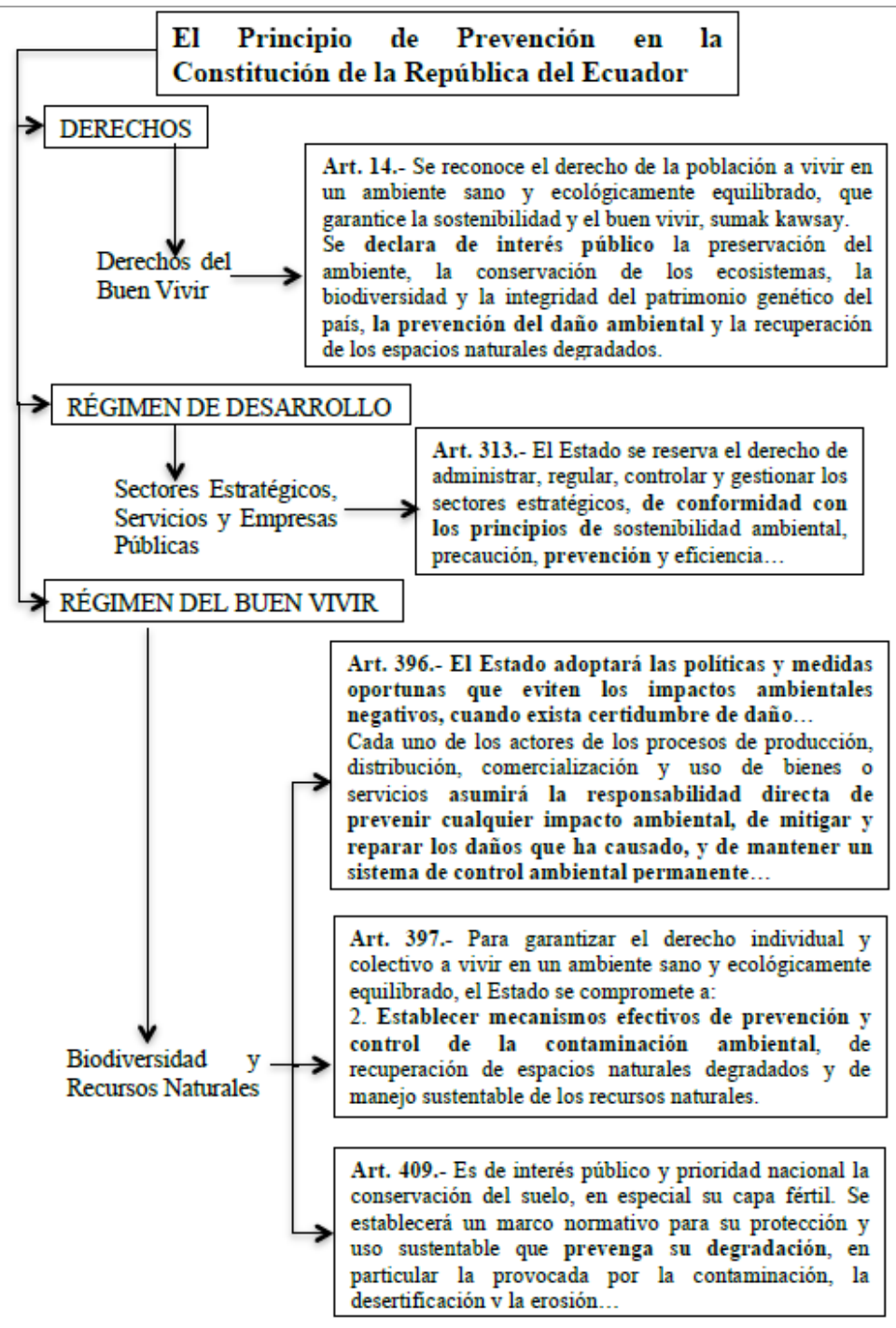

Figura 4. Principios de la preservación del ecosistema y

ambiente sano en la Constitución del República del Ecuador.

Fuente: (Baquero Correa, 2015)

Cuando la sociedad empieza a forjar sus soluciones en pro del bien común sin tomar en cuenta las repercusiones de sus actos, más si es contra el ecosistema, entonces hay un delito ambiental en curso. Como existen leyes y normas, estas deben actuar en pro del cuidado y 


\section{Subsistema de áreas naturales protegidas para enfrentar delitos ambientales contra la fauna del cantón Quevedo}

Vol. 3, núm. 3., (2019)

Karen Mercedes Barragán Monrroy; Holger Bolívar Alvarado Onofre

bienestar del medio ambiente. Los elementos naturales como objetos directos de la acción delictiva y exigen una afectación, bien de la salud de las personas, bien de las condiciones de la vida animal, bosques, espacios naturales o plantaciones útiles(De la Cuesta Arzamendi, 2009).

Pero cuando se llevan ante la ley este tipo de delitos pues son considerados, por muchos, como delitos penales en blanco ya que se deben cumplir una serie de pasos que tienden a ser burocráticos y que por diversas razones no se cumplen entonces dichas faltas no pasan de ser llamados de atención. Estos delitos penales en blanco son por las normas administrativas o por los informes técnicos legales elaborados por las autoridades ambientales de la región(Portilla, 2010).Los juicios morales y las atribuciones sobre los motivos de la acción constituyen los procesos que parecen sostener la categorización del delito ecológico(Hernández, y otros, 2005).

Ahora, según la jurisprudencia estos delitos son subjetivos o a decir verdad de naturaleza abstracta. De modo que no es necesario verificar un resultado material externo, ni tampoco que se haya puesto en peligro concreto el medio ambiente basta con que en un juicio ex ante quepa afirmar la peligrosidad de la conducta(García Sanz, 2008).

"De modo que el problema no es la ausencia deinstrumentos jurídicos, tampoco la falta de conocimientos científicos acerca de laorganización y funcionamiento de los ecosistemas naturales y del impacto de lasactividades humanas sobre los componentes de la biosfera, y la propia salud u bienestardel hombre. El problema es de naturaleza política, tiene que ver con el poder político delos Estados y el económico de las poderosas corporaciones multinacionales y globales”.(Meier, 2007, pág. 32) 


\section{Subsistema de áreas naturales protegidas para enfrentar delitos ambientales contra la fauna del cantón Quevedo}

Vol. 3, núm. 3., (2019)

Karen Mercedes Barragán Monrroy; Holger Bolívar Alvarado Onofre

Al mismo tiempo de que existan estas fallas tecnojurídicas, es necesario llegar a la reflexión si el hombre es el primer catalizador para estos problemas ambientales. Se debe aplicar un cambio de valores, cultural y moral en las sociedades actuales. Se debe encontrar un equilibrio material donde el desarrollo tecnológicosea una respuesta a las necesidades sociales reales más que a las demandas creadasartificialmente, los cuales pueden beneficios acorto plazo, pero con efectos negativos sobre el ecosistema y biodiversidad(Pazmiño, 2011).

En definitiva, existe una relevancia importante que radica en el análisis crítico jurídico de las acciones de protección del subsistema de áreas naturales, y las sanciones que pueden recibir las personas que están atentando contra la fauna silvestre, además cuales son las reparaciones que deben realizar, ya que estos delitos están destruyendo el hábitat natural de la fauna silvestre, lo que genera la extinción de algunas especies en peligro, siendo alarmante porque la naturaleza es esencial para la vida de cualquier especie, y muchas personas prefieren enriquecerse sin medir las consecuencias.

Por lo tanto, el objetivo general de esta investigación es analizar los subsistemas de áreas naturales protegidas para enfrentar delitos ambientales contra la fauna del cantón Quevedo. La metodología aplicada se basó en investigaciones de tipo cuali-cuantitativa.

\section{Método.}

La metodología que se empleará en el presente artículo científico es cuali-cuantitativa, pues se asumen elementos y lógicas de ambas modalidades para poder sustentar los elementos de carácter empírico que evidencian la problemática estudiada: 


\section{Subsistema de áreas naturales protegidas para enfrentar delitos ambientales contra la fauna del cantón Quevedo}

Vol. 3, núm. 3., (2019)

Karen Mercedes Barragán Monrroy; Holger Bolívar Alvarado Onofre

Método Histórico - Lógico, se empleará para el análisis de la evolución histórica de los Derechos de la naturaleza que se han sido implementados hasta la actualidad, el cual permitirá establecer su origen y las principales etapas para descubrir cómo ha evolucionado el problema, ya que es un proceso que muestra carencia en la reparación integral por los daños ambientales de las actividades antropogénicas realizadas.

MétodoAnalítico - Sintético, se utilizará fundamentalmente para el análisis de los fundamentos que en el orden teórico sostienen la investigación, el mismo permite revisar e identificar de manera precisa como aplicar la reparación integral a la fauna silvestre y tomar los apuntes necesarios en cuanto a las teorías, paradigmas, conceptualizaciones entre otras.

Método Inductivo - Deductivo, permitirá observar las situaciones que afectan las áreas naturales y así obtener conclusiones del problema abordado, permitiendo catalogar la incongruencia de los factores que repercuten a la fauna silvestre del cantón Quevedo; y el deductivo, servirá para evidenciar la problemática, definir los objetivos que darán respuesta a las preguntas planteadas y realizar conclusiones de acuerdo a los resultados obtenidos para poder viabilizar la solución.

\section{Resultados}

Las áreas naturales protegidas del Ecuador

Ecuador presenta una diversidad de climas y por consecuencia una gran cantidad de flora fauna que la hacen una de las naciones con mayor biodiversidad del planeta. Esta diversidad está influenciada por los efectos orográficos del levantamiento de las Cordilleras de los Andes y de la Costa; la circulación general atmosférica (con influencias del Océano Pacífico y de la cuenca 


\section{Subsistema de áreas naturales protegidas para enfrentar delitos ambientales contra la fauna del cantón Quevedo}

Vol. 3, núm. 3., (2019)

Karen Mercedes Barragán Monrroy; Holger Bolívar Alvarado Onofre amazónica) y la influencia de las corrientes marinas en las costas(Ministerio-del-Ambiente-delEcuador, Estrategia Nacional de Biodiversidad 2015-2030, 2019). En la Tabla 2 se detalla la diversidad biogeográfica del Ecuador Continental.

Tabla 2. Diversidad biogeográfica del Ecuador Continental

\begin{tabular}{|c|c|c|c|}
\hline $\begin{array}{l}\text { Reglones } \\
\text { blogeográficas }\end{array}$ & 1. Amazonla & 2. Andes & Litoral \\
\hline $\begin{array}{l}\text { Provinclas } \\
\text { blogeográflicas }\end{array}$ & 1. Amazonía Noroccidental & 2. Andes del Norte Chocó & 3. Pacífico Ecuatorial \\
\hline $\begin{array}{l}\text { Sectores } \\
\text { blogeográficos }\end{array}$ & $\begin{array}{l}\text { 1. Abanico del Pastaza } \\
\text { 2. Aguarico-Putumayo- } \\
\text { Caquetá } \\
\text { 3. Catamayo Alamor } \\
\text { 4. Choco Ecuatorial } \\
\text { 5. Cordillera Costera del } \\
\text { Choco }\end{array}$ & $\begin{array}{l}\text { 6. Cordillera Costera del } \\
\text { Pacífico Ecuatorial } \\
\text { 7. Cordillera Occidental } \\
\text { 8. Cordilleras Amazónicas } \\
\text { 9. Jama-Zapotillo } \\
\text { 10. Napo-Curaray }\end{array}$ & $\begin{array}{l}\text { 11. Norte de la Cordillera } \\
\text { Oriental } \\
\text { 12. Páramo } \\
\text { 13. Sur de la Cordillera } \\
\text { Oriental } \\
\text { 14. Tigre-Pastaza } \\
\text { 15. Valles }\end{array}$ \\
\hline
\end{tabular}

Fuente: (Ministerio-del-Ambiente-del-Ecuador, Estrategia Nacional de Biodiversidad 20152030, 2019)

En el Ecuador existen una variada cantidad de ecosistemas que están distribuidos por provincias, bajo sistema de protección nacional y dentro de los parques nacionales. Estos se pueden visualizar a través de las Tabla 3, 4 y 5, respectivamente. En dichas tablas se puede observar como la provincia de Morona Santiago tiene mayores ecosistemas en el país, con 31, y la provincia de Los Ríos conjuntamente con las zonas no delimitadas son las que tienen menores ecosistemas, con 9 y 8; también el sistema Nacional de Áreas Protegidas son los que tienen 


\section{Subsistema de áreas naturales protegidas para enfrentar delitos ambientales contra la fauna del cantón Quevedo}

Vol. 3, núm. 3., (2019)

Karen Mercedes Barragán Monrroy; Holger Bolívar Alvarado Onofre

mayor superficie protegida; y el Parque Nacional Sangay tiene 19 ecosistemas dentro de su territorio haciéndolo más biodiverso en todo Ecuador.

Tabla 3. Ecosistemas por provincias

\begin{tabular}{|c|c|c|c|c|c|}
\hline Provincias & $\begin{array}{l}\text { Número de } \\
\text { Ecosistemas }\end{array}$ & $\begin{array}{l}\text { Porcentaje } \\
\text { provincial" }\end{array}$ & $\begin{array}{l}\text { Númer } \\
\text { Ecosiste }\end{array}$ & $\begin{array}{l}\text { de } \\
\text { has }\end{array}$ & $\begin{array}{l}\text { Porcentaje } \\
\text { provincial }^{*}\end{array}$ \\
\hline Azuay & 20 & $53,3 \%$ & Manabí & 16 & $53,3 \%$ \\
\hline Bolivar & 15 & $29,3 \%$ & Morona Santiago & 31 & $81,6 \%$ \\
\hline Cañar & 14 & $38,6 \%$ & Napo & 18 & $85,6 \%$ \\
\hline Carchi & 13 & $49,5 \%$ & Orellana & 17 & $87,9 \%$ \\
\hline Chimborazo & 17 & $45,0 \%$ & Pastaza & 15 & $94,8 \%$ \\
\hline Cotopaxi & 15 & $39,3 \%$ & Pichincha & 17 & $44,6 \%$ \\
\hline 日Oro & 19 & $28,9 \%$ & Santa Bena & 11 & $72,8 \%$ \\
\hline Esmeraldas & 14 & $53,5 \%$ & Santo Domingo & 5 & $9.6 \%$ \\
\hline Guayas & 15 & $40,2 \%$ & Sucumbios & 17 & $81,6 \%$ \\
\hline Imbabura & 13 & $45,4 \%$ & Tungurahua & 15 & $62,6 \%$ \\
\hline Loja & 21 & $54,5 \%$ & Zamora Chinchipe & 18 & $78,8 \%$ \\
\hline Los Ríos & 9 & $33,6 \%$ & $\begin{array}{l}\text { Zonas no } \\
\text { delimitadas }\end{array}$ & 8 & $12,7 \%$ \\
\hline
\end{tabular}

Fuente: (Ministerio-del-Ambiente-del-Ecuador, Estadísticas del Patrimonio Natural, 2019)

Tabla 4. Ecosistemas en áreas bajo conservación a nivel nacional

\begin{tabular}{|lccc|}
\hline Categoria & $N^{0}$ de Ecosistemas & Superficie(ha) & Porcentaje * \\
\hline $\begin{array}{l}\text { Amortiguamiento } \\
\text { Yasuní }\end{array}$ & 7 & $213.501,81$ & $2,79 \%$ \\
\hline Bosques protectores & 67 & $1 ' 641.967,83$ & $21,52 \%$ \\
\hline Patrimonio forestal & 25 & $748.751,25$ & $9,81 \%$ \\
\hline SNAP pstema Nacional de íveas Protegidas) & 68 & $3 ' 991.915,22$ & $52,33 \%$ \\
\hline Socio Bosque & 72 & $906.673,04$ & $11,88 \%$ \\
\hline Zona intangible & 9 & $124.514,11$ & $1,63 \%$ \\
\hline
\end{tabular}

Fuente: (Ministerio-del-Ambiente-del-Ecuador, Estadísticas del Patrimonio Natural, 2019) 


\section{Subsistema de áreas naturales protegidas para enfrentar delitos ambientales contra la fauna del cantón Quevedo}

Vol. 3, núm. 3., (2019)

Karen Mercedes Barragán Monrroy; Holger Bolívar Alvarado Onofre

Tabla 5. Parques Nacionales con mayor número de Ecosistemas

\begin{tabular}{|lc|lc|}
\cline { 3 - 4 } Parque Nacional & $\begin{array}{c}N^{\circ} \text { de } \\
\text { Ecosistemas }\end{array}$ & Parque Nacional & $\begin{array}{c}\mathrm{N}^{\circ} \text { de } \\
\text { Ecosistemas }\end{array}$ \\
\hline Sangay & 19 & Yasuni & 9 \\
Podocarpus & 12 & Machalilla & 9 \\
Llanganates & 10 & Yacuri & 8 \\
Cotopaxi & 10 & Sumaco Napo-Galeras & 8 \\
Cayambe Coca & 10 & Cajas & 4 \\
\hline
\end{tabular}

Fuente: (Ministerio-del-Ambiente-del-Ecuador, Estadísticas del Patrimonio Natural, 2019)

Uno de los organismos encargados de velar por la conservación y preservación de las áreas naturales en el Ecuador es el Sistema Nacional de Áreas Protegidas (SNAP) el cual posee 68 ecosistemas importantes en el país. El SNAP es el conjunto de áreas naturales que garantizanla cobertura y conectividad de ecosistemas terrestres, marinos y marino-costeros, de sus recursos culturales y de las principales fuentes hídricas(Ministerio-del-Ambiente-delEcuador, Áreas protegidas del Ecuador socio estrategico para el desarrollo, 2019).

El SNAP, para el 2015, abarcan las 4 regiones del país dentro 20 provincias, por lo que es el principal organismo encargado de la conservación de la biodiversidad ecuatoriana. Está constituido por: 11 Parques Nacionales, 5 Reservas Biológicas, 1 Reserva Geobotánica, 9 Reservas Ecológicas, 4 Reservas Marinas, 6 Áreas Nacionales de Recreación, 4 Reservas de Producción de Fauna, 10 Refugios de Vida Silvestre y 1 Área Ecológica de Conservación Municipal(Ministerio-del-Ambiente-del-Ecuador, Áreas protegidas del Ecuador socio estrategico para el desarrollo, 2019), El SNAP se puede visualizar a través de la Figura 5. 


\section{Subsistema de áreas naturales protegidas para enfrentar delitos ambientales contra la fauna del cantón Quevedo}

Vol. 3, núm. 3., (2019)

Karen Mercedes Barragán Monrroy; Holger Bolívar Alvarado Onofre

La SNAP debe buscar siempre las mejores estrategias, tanto civiles como jurídicas, para

la conservación de las áreas más vulnerables. En la Tabla 6, se consideras los preceptos más

fundamentales para la conservación y preservación de los espacios naturales y su biodiversidad.

Tabla 6. Preceptos fundamentales para la conservación y preservación de los espacios

naturales y su biodiversidad

\begin{tabular}{l} 
El mantener la integridad funcional que debe tener el SNAP, tanto en el ámbito \\
ecológico como administrativo, para el cumplimiento de los objetivos principales del \\
mismo, especialmente: conservar la biodiversidad existente en las áreas protegidas y \\
mantener la generación de bienes y servicios ambientales de los ecosistemas \\
existentes en las mismas \\
\hline El fortalecimiento del Ministerio del Ambiente como autoridad ambiental y la \\
consolidación de su capacidad de: definir políticas, normas y reglamentos; aplicar, \\
evaluar y dar seguimiento a la normativa ambiental y sancionar sus infracciones. \\
\hline La amplia y directa participación (corresponsabilidad), con deberes y derechos \\
específicos, de todos los actores involucrados en el tema de las áreas protegidas, \\
tanto de organismos y entidades estatales y privadas comprometidas con su \\
conservación, así como de las comunidades que habitan en las áreas o en sus zonas \\
de amortiguamiento y/o influencia, entre otros actores. \\
\hline El mejoramiento y fortalecimiento de las capacidades de los diversos actores \\
involucrados en la gestión de las áreas protegidas. \\
\hline El costo del manejo y administración de las áreas protegidas y de la conservación de \\
su biodiversidad no puede ser cubierto exclusivamente con fondos gubernamentales. \\
Se requiere, por tanto, el apoyo de otras fuentes adicionales de financiamiento \\
provenientes de gobiernos seccionales, organizaciones no gubernamentales, \\
empresas privadas, organismos de apoyo internacional entre otros. \\
Los daños ambientales y afectación de los recursos naturales de las áreas protegidas \\
son procesos, en la mayoría de casos, de carácter irreversible y de efectos \\
colaterales incalculables.
\end{tabular}

Fuente: (Ulloa, y otros, 2003)

El SNAP debe seguir en una constante transformación y cambios que permitan conseguir sus objetivos dentro del plan estratégico de la nación. Para ello, es necesario poder visualizar las fortalezas y debilidad y con ello seguir construyendo las oportunidades necesarias para la transformación sin olvidar las amenazas que conllevan tales acciones. Estas fortalezas y debilidades se pueden visualizar en la Tabla 7. 


\section{Subsistema de áreas naturales protegidas para enfrentar delitos ambientales contra la fauna del cantón Quevedo}

Vol. 3, núm. 3., (2019)

Karen Mercedes Barragán Monrroy; Holger Bolívar Alvarado Onofre

Tabla 7. Fortalezas y debilidades de la SNAP

\begin{tabular}{|c|}
\hline FORTALEZAS \\
\hline $\begin{array}{l}\text { La Autoridad Ambiental Nacional funciona con el } \\
\text { sustento legal apropiado (Constitución, Ley } \\
\text { Forestal, Reglamentos) y es reconocida como tal al } \\
\text { nivel nacional. }\end{array}$ \\
\hline
\end{tabular}

La actual estructura ha permitido que las oficinas regionales adapten su gestión a las condiciones locales, logrando mejores resultados y consiguiendo más apoyo político.

El SNAP no se relaciona totalmente con los objetivos nacionales de conservación, con el mandato constitucional y legal, ni con los compromisos internacionales que están orientados a la conservación de recursos naturales, biológicos y culturales, participación de la comunidad y reducción de los niveles de pobreza.

Las diferentes iniciativas de conservación en áreas protegidas (áreas estatales, áreas protegidas privadas y bosques protectores) no se complementan ni relacionan entre sí, funcionando como elementos aislados e independientes.

La gestión del SNAP cubre de manera limitada aspectos como la restauración, el aprovechamiento

En general, existe una actitud proactiva de la mayoría de los funcionarios del MAE, respecto a enfrentar problemas administrativos y operativos y a cumplir sus programas superando limitaciones económicas y de apoyo técnico. sustentable de la biodiversidad, fomento de alternativas productivas sustentables y protección de las fuentes de captación de agua, lo que conlleva a la escasa valoración del papel de las áreas protegidas del país por parte de la población, que se traduce en un insuficiente apoyo social, político y financiero al SNAP.

Existe un alto número de técnicos con un buen nivel de capacitación y experiencia en el manejo de las diferentes unidades de conservación del sistema.

Se ha aprovechado las facilidades para asociarse con una gran cantidad de instituciones de apoyo técnico, financiero y político, lo que ha redundado en el cumplimiento de metas y objetivos.

Fuente: (Ministerio-del-Ambiente-del-Ecuador, Plan Estratégico del Sistema Nacional de Áreas Protegidas del Ecuador 2007-2016, 2019) 


\section{Subsistema de áreas naturales protegidas para enfrentar delitos ambientales contra la fauna del cantón Quevedo}

Vol. 3, núm. 3., (2019)

Karen Mercedes Barragán Monrroy; Holger Bolívar Alvarado Onofre

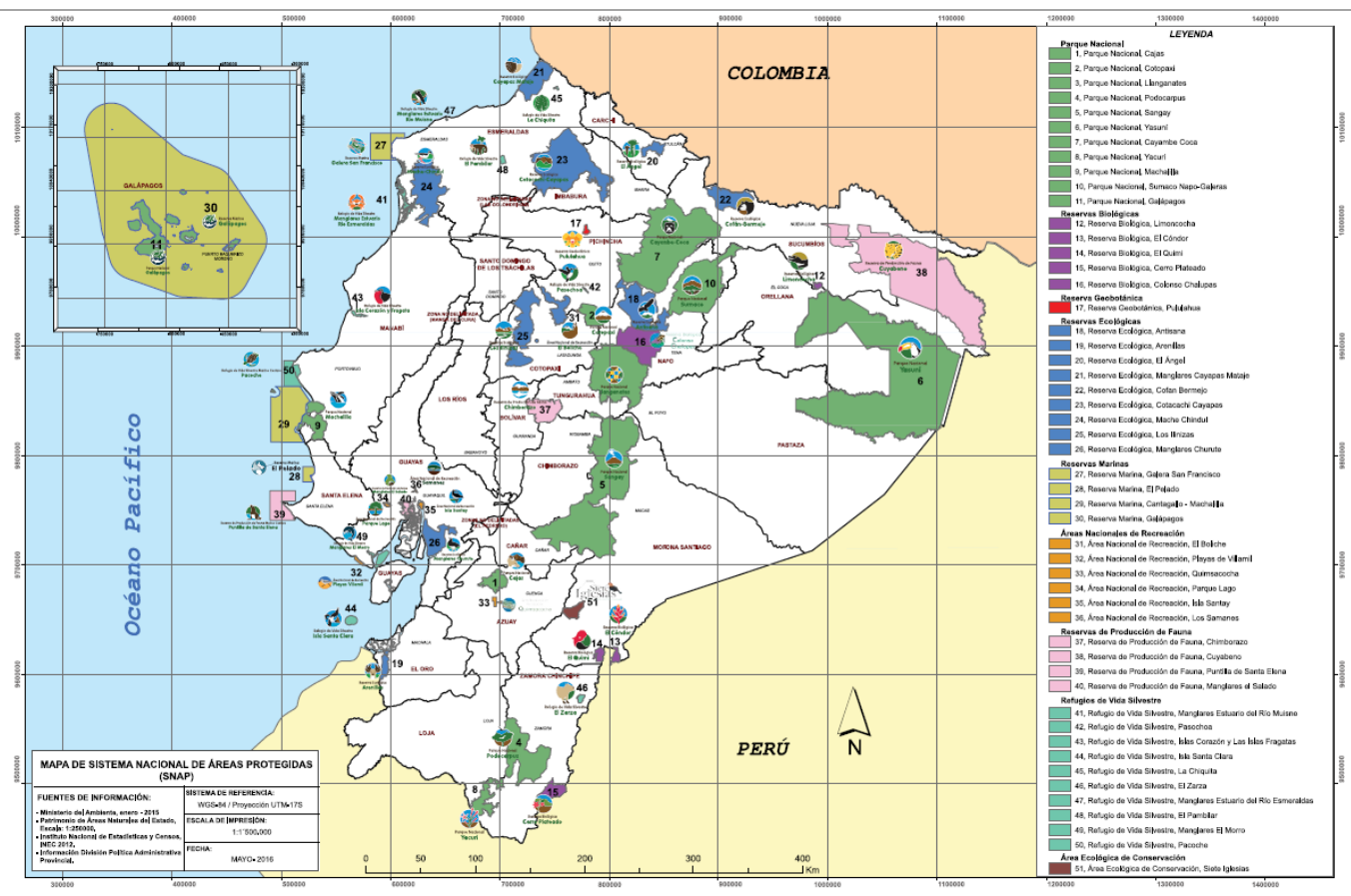

Figura 5. Mapa del Sistema Nacional de Áreas Protegidas

Fuente: (Ministerio-del-Ambiente-del-Ecuador, Áreas protegidas del Ecuador socio estrategico para el desarrollo, 2019)

Existen dentro del SNAP dos formas de subsistemas, uno de forma pública y el otro privado.

“El subsistema estatal recibe la denominación de Patrimonio de Áreas Naturales del Estado (PANE). Este subsistema abarca 48 áreas protegidas que representan aproximadamente el $20 \%$ del territorio nacional. A su vez, el Ministerio del Ambiente, considera clave el involucramiento de la sociedad en las acciones de conservación a través del Subsistema de Áreas protegidas privadas (APPRI)".(Ministerio-del-Ambiente-del-Ecuador, SUBSISTEMAS DE AREAS NATURALES PROTEGIDAS, 2019) 


\section{Subsistema de áreas naturales protegidas para enfrentar delitos ambientales contra la fauna del cantón Quevedo}

Vol. 3, núm. 3., (2019)

Karen Mercedes Barragán Monrroy; Holger Bolívar Alvarado Onofre

Ahora, es importante también vincular la fauna presente en estas áreas y de las cuales son vulnerables a todos los efectos del impacto ambiental. En Ecuador la información más reciente sobre el número de especies de vertebrados indica que al momento se registran 4.858 especies(Ministerio-del-Ambiente-del-Ecuador, Estrategia Nacional de Biodiversidad 20152030, 2019). En la Tabla 8 se muestra el número de especies reportadas a nivel global y para el Ecuador.

Tabla 8. Número de especies reportadas a nivel global y para el Ecuador

\begin{tabular}{|c|c|c|c|}
\hline \multirow{2}{*}{ GRUPO TAXONÓMICO } & \multicolumn{3}{|c|}{ NÚMERO DE ESPECIES } \\
\hline & CLOBAL & ECUADOR & PORCENTAUE \\
\hline Plantas vasculares* & 320.000 & 18.198 & 5,7 \\
\hline Peces marinos & 16.000 & 833 & 5,2 \\
\hline Peces dulceacuícolas & 12.000 & 951 & 7,9 \\
\hline Anfibios & 6.888 & 558 & 8,1 \\
\hline Reptiles & 9.413 & 450 & 4,8 \\
\hline Aves & 10.052 & 1.642 & 16,3 \\
\hline Mamíferos & 5.488 & 424 & 7,6 \\
\hline Total & 379.841 & 23.056 & 6,1 \\
\hline
\end{tabular}

Fuente: (Ministerio-del-Ambiente-del-Ecuador, Estrategia Nacional de Biodiversidad 20152030, 2019)

El ecosistema y biodiversidad de la Provincia de Los Ríos, Ecuador

Una de las provincias que conforman el territorio ecuatoriano es la de Los Ríos. La población tiene unas características reflejadas en la Figura 6. La población total de esta provincia 


\section{Subsistema de áreas naturales protegidas para enfrentar delitos ambientales contra la fauna del cantón Quevedo}

Vol. 3, núm. 3., (2019)

Karen Mercedes Barragán Monrroy; Holger Bolívar Alvarado Onofre

es de 380016 mujeres y 398099 hombres según el censo realizado por Instituto Nacional de Estadísticas y Censos (INEC) del Ecuador, mostrado en la Figura 7.

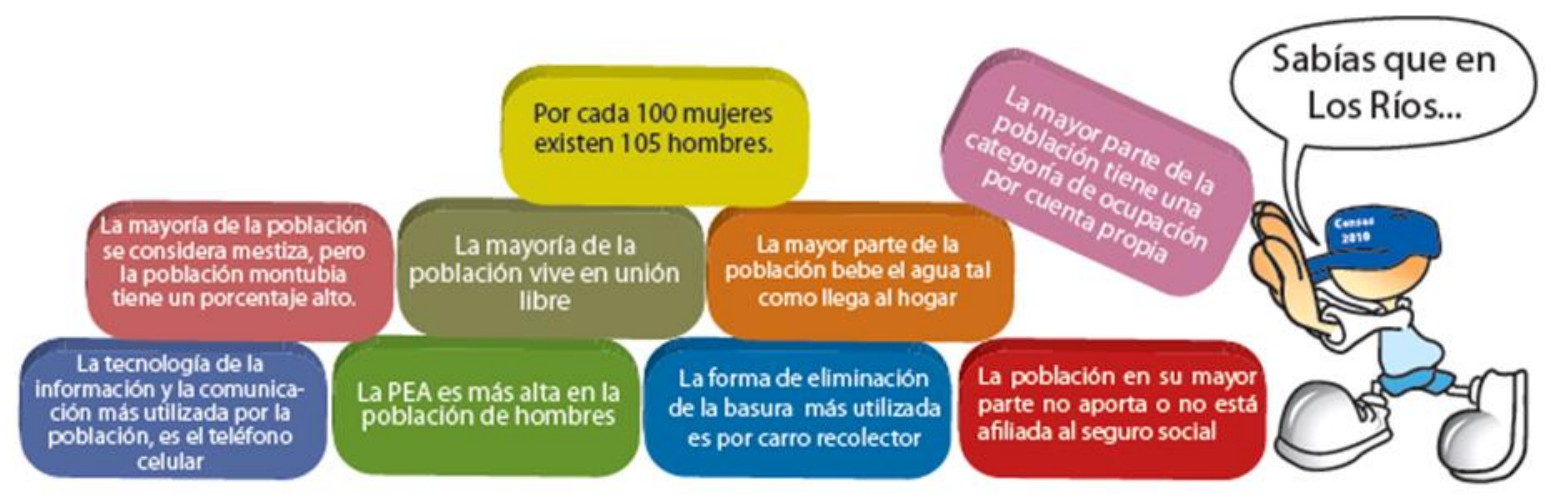

Figura 6. Características de a Población de la provincia de Los Rios, Ecuador

Fuente: (INEC, 2019)

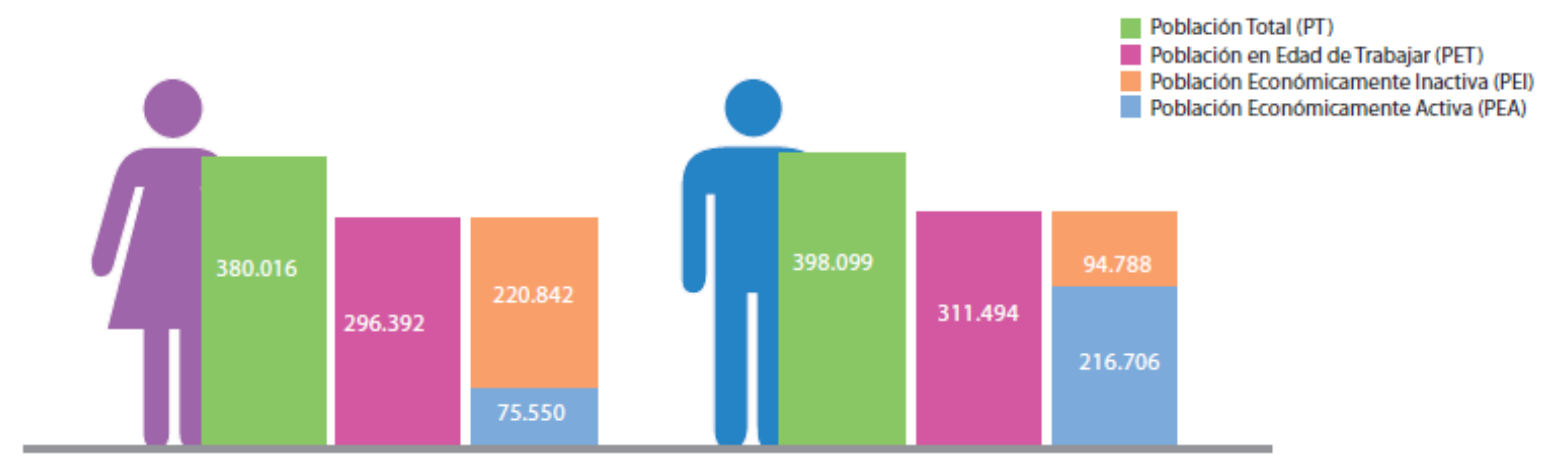

* La Población en Edad de Trabajar y la PEA se calculan para las personas de 10 años de edad y más.

Figura 7. Estructura de la Población económicamente activa en la provincia Los Ríos, Ecuador.

Fuente: (INEC, 2019)

La provincia de Los Ríos tiene 13 cantones destacando, por densidad poblacional,

Quevedo, Babahoyo, Vinces y Ventanas. Las características en función de condición donde 


\section{Subsistema de áreas naturales protegidas para enfrentar delitos ambientales contra la fauna del cantón Quevedo}

Vol. 3, núm. 3., (2019)

Karen Mercedes Barragán Monrroy; Holger Bolívar Alvarado Onofre

viven, tipo de vivienda, razón de niños mujeres y analfabetismo, para el año 2010, se pueden visualizar en la Tabla 9.

Tabla 9. Situación a nivel de los cantones de la provincia de Los Ríos

\begin{tabular}{|c|c|c|c|c|c|c|c|c|c|c|c|}
\hline Cantones & Hombres & 96 & Mujeres & $\%$ & Total & Urbano & Rural & Viviendasth & $\begin{array}{l}\text { Razón nifíos } \\
\text { mujeres * }\end{array}$ & Analfabetismo & $\begin{array}{l}\text { Edad } \\
\text { promedio }\end{array}$ \\
\hline Baba & 20.765 & $5,2 \%$ & 18.916 & $5,0 \%$ & 39.681 & 5.368 & 34.313 & 11.967 & 475,4 & $14,5 \%$ & 28 \\
\hline Babahoyo & 77.967 & $19,6 \%$ & 75.809 & $19,9 \%$ & 153.776 & 90.191 & 63.585 & 47.361 & 382,5 & $6,7 \%$ & 28 \\
\hline Urdaneta & 15.063 & $3,8 \%$ & 14.200 & $3,7 \%$ & 29.263 & 6.240 & 23.023 & 8.959 & 443,3 & $10,1 \%$ & 29 \\
\hline Mocache & 19.996 & $5,0 \%$ & 18.396 & $4,8 \%$ & 38.392 & 8.028 & 30.364 & 11.516 & 479,5 & $13,5 \%$ & 28 \\
\hline Montalvo & 12.298 & $3,1 \%$ & 11.866 & $3,1 \%$ & 24.164 & 12.734 & 11.430 & 7.990 & 377,1 & $6,2 \%$ & 29 \\
\hline Palenque & 11.841 & $3,0 \%$ & 10.479 & $2,8 \%$ & 22.320 & 6.348 & 15.972 & 7.172 & 522,8 & $18,1 \%$ & 28 \\
\hline Puebloviejo & 18.614 & $4,7 \%$ & 17.863 & $4,7 \%$ & 36.477 & 7.871 & 28.606 & 10.837 & 472,1 & $10,6 \%$ & 26 \\
\hline Quevedo & 86.821 & $21,8 \%$ & 86.754 & $22,8 \%$ & 173.575 & 150.827 & 22.748 & 50.583 & 394,0 & $6,3 \%$ & 27 \\
\hline Quinsaloma & 8.627 & $2,2 \%$ & 7.849 & $2,1 \%$ & 16.476 & 4.573 & 11.903 & 5.051 & 492,3 & $11,8 \%$ & 27 \\
\hline San Jacinto de Buena Fe & 32.649 & $8,2 \%$ & 30.499 & $8,0 \%$ & 63.148 & 38.263 & 24.885 & 17.461 & 474,0 & $10,8 \%$ & 26 \\
\hline Valencia & 22.592 & $5,7 \%$ & 19.964 & $5,3 \%$ & 42.556 & 16.983 & 25.573 & 12.056 & 497,4 & $12,5 \%$ & 26 \\
\hline Ventanas & 33.785 & $8,5 \%$ & 32.766 & $8,6 \%$ & 66.551 & 38.168 & 28.383 & 19.771 & 448,4 & $8,5 \%$ & 27 \\
\hline Vinces & 37.081 & $9,3 \%$ & 34.655 & $9,1 \%$ & 71.736 & 30.248 & 41.488 & 21.742 & 450,4 & $11,4 \%$ & 29 \\
\hline Total & 398.099 & $100 \%$ & 380.016 & $100 \%$ & 778.115 & 415.842 & 362.273 & 232.466 & & & \\
\hline
\end{tabular}

Fuente: (INEC, 2019)

Ahora, la provincia de Los Ríos no posee un área natural protegida según el mapa de la SNAP del Ecuador como se muestra en la Figura 5, pero posee un área natural muy importante en la zona que es el Humedal Abras de Mantequilla. Las características del Humedal Abras de Mantequilla se pueden visualizar en la Tabla 10.

"Se encuentra en la cuenca alta del Golfo de Guayaquil, que comprende la provincia de Los Ríos, siendo su máximo tributario el río Quevedo, en la región Costera el Ecuador. Está rodeado por tres importantes cantones que han desarrollado urbanísticamente sus ciudades en el margen del humedal. Estas ciudades son las de Vinces, Baba y Pueblo Viejo”.(Quevedo Pino, 2019, pág. 2) 


\section{Subsistema de áreas naturales protegidas para enfrentar delitos ambientales contra la fauna del cantón Quevedo}

Vol. 3, núm. 3., (2019)

Karen Mercedes Barragán Monrroy; Holger Bolívar Alvarado Onofre

Tabla 10. Características del Humedal Abras de Mantequilla, provincia de Los Ríos

\begin{tabular}{|c|c|}
\hline DESCRIPCIÓN & CARACTERÍSTICAS \\
\hline $\begin{array}{c}\text { Localización } \\
\text { Geográfica }\end{array}$ & $\begin{array}{l}\text { Las Abras están localizadas en la provincia de Los Ríos, en la costa } \\
\text { ecuatoriana, los límites provinciales son Guayas, Manabí, Bolívar, Cotopaxi y } \\
\text { Pichincha. Su jurisdicción la conforman los cantones Vinces, Baba y Pueblo } \\
\text { Viejo. Las principales abras o lagunas estacionales son: Mantequilla, } \\
\text { Cimarrón, El Garzal, Zapallo y San Juan. }\end{array}$ \\
\hline Altitud & La altura varía entre $30-60$ m. s.n.m \\
\hline Área & 67.177 has. \\
\hline $\begin{array}{c}\text { Descripción general del } \\
\text { sitio }\end{array}$ & $\begin{array}{l}\text { Las lagunas de Abras de Mantequilla, El Garzal, Mapancillo y San Juan son de } \\
\text { carácter estacional, aproximadamente durante ocho meses del año el volumen } \\
\text { que albergan comienza a descender hacia finales de octubre y noviembre. } \\
\text { Durante la época lluviosa el volumen de agua inunda aproximadamente de } 5 \text { a } \\
8 \text { metros de profundidad con meandros de hasta cien metros de ancho, el } \\
\text { desbordamiento del río Vinces, Quevedo, y Puebloviejo alimentan esta gran } \\
\text { llanura con topografía de variados relieves entre } 20 \text { y } 30 \text { m. s.n.m. } \\
\text { aproximadamente que se van abriendo paso y creando formaciones dendrítico - } \\
\text { acuosas. El sitio genera una alta producción arrocera durante la estación seca, } \\
\text { ya que se cultiva en sistema de terraza, es decir a medida que el agua va } \\
\text { descendiendo los campesinos proceden a sembrar y cuando el agua a } \\
\text { alcanzado su máximo nivel se utilizan las cimas de los montes para sembrar } \\
\text { maíz. Aún en el sitio persisten remanentes de bosque Seco Tropical, los cuales } \\
\text { son utilizados en el desarrollo de alternativas turísticas. }\end{array}$ \\
\hline $\begin{array}{l}\text { Características } \\
\text { Ambientales }\end{array}$ & $\begin{array}{l}\text { La zona de estudio está dentro de la zona de vida del Bosque Semi- Deciduo } \\
\text { de Llanura de la Costa, o Bosque Seco Tropical. La temperatura promedio } \\
\text { durante todo el año es de } 25^{\circ} \text { C. siendo los meses más calientes: diciembre, } \\
\text { enero, febrero, marzo y abril; que corresponden al invierno. La humedad } \\
\text { promedio es de } 82 \% \text {, asimismo acentuándose en los meses de invierno y } \\
\text { postinvierno. Hay una precipitación de } 1260 \mathrm{~mm} \text {. anuales, con un promedio de } \\
116 \text { días de lluvia. }\end{array}$ \\
\hline $\begin{array}{l}\text { Criterio basado en } \\
\text { especies: Aves }\end{array}$ & $\begin{array}{l}\text { Abras de Mantequilla fue designada como un área de Importancia para la } \\
\text { Conservación de las Aves (IBA's) para lo cual se reportó un total de } 127 \\
\text { especies en el humedal y en los bosques circundantes, alberga demás } 20 \\
\text { especies acuáticas congregatorias, y puede ser un sitio importante para varias } \\
\text { de ellas. Para la región tumbesina se identificaron quince especies de aves de } \\
\text { las } 48 \text { especies presentes en Ecuador dentro de esta área de Endemismo de } \\
\text { Aves. } \\
\text { Especies clave: } \\
\text { Crypturellustransfasciatus } \mathbf{N T ( C a s i ~ A m e n a z a d a ) ~} \\
\text { Leucopternisoccidentalis EN(En Peligro) } \\
\text { Brotogerispyrrhopterus } \mathbf{E N ( E n ~ P e l i g r o ) ~} \\
\text { Acestrurabombus VU (Vulnerable) } \\
\text { Pachyramphusspodiurus } \mathbf{E N ( E n ~ P e l i g r o ) ~}\end{array}$ \\
\hline $\begin{array}{l}\text { Criterio basado en } \\
\text { especies: Peces }\end{array}$ & 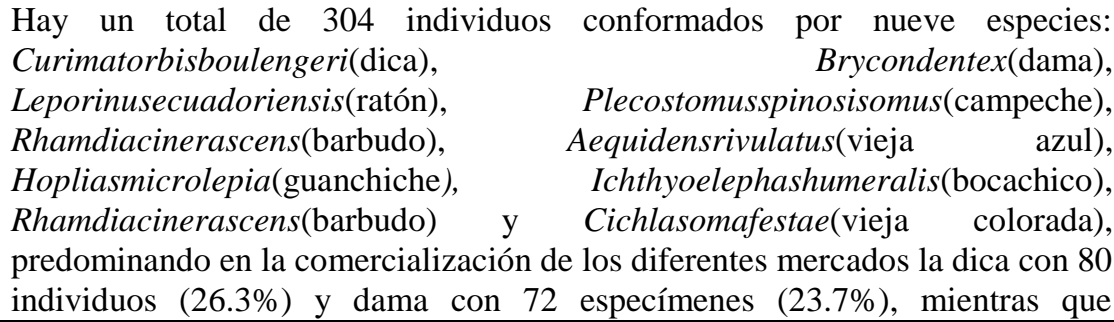 \\
\hline
\end{tabular}




\section{Subsistema de áreas naturales protegidas para enfrentar delitos ambientales contra la fauna del cantón Quevedo}

Vol. 3, núm. 3., (2019)

Karen Mercedes Barragán Monrroy; Holger Bolívar Alvarado Onofre

campeche fue la menos comercializada $(0.3 \%)$.

La fauna zooplanctónica estuvo constituida por siete taxas en total, donde los rotíferos fueron los más abundantes (52\%), seguidos por crustáceos con el $24 \%$ e insectos $19 \%$, siendo de menor valor relativo los cnidarios, gasterópodos, nermetea e hydracarinas

Fuente: (Quevedo Pino, 2019)

La localización del Humedal Abras de Mantequilla se puede observar través de la Figura 8, donde se muestra el mapa de la provincia Los Ríos.

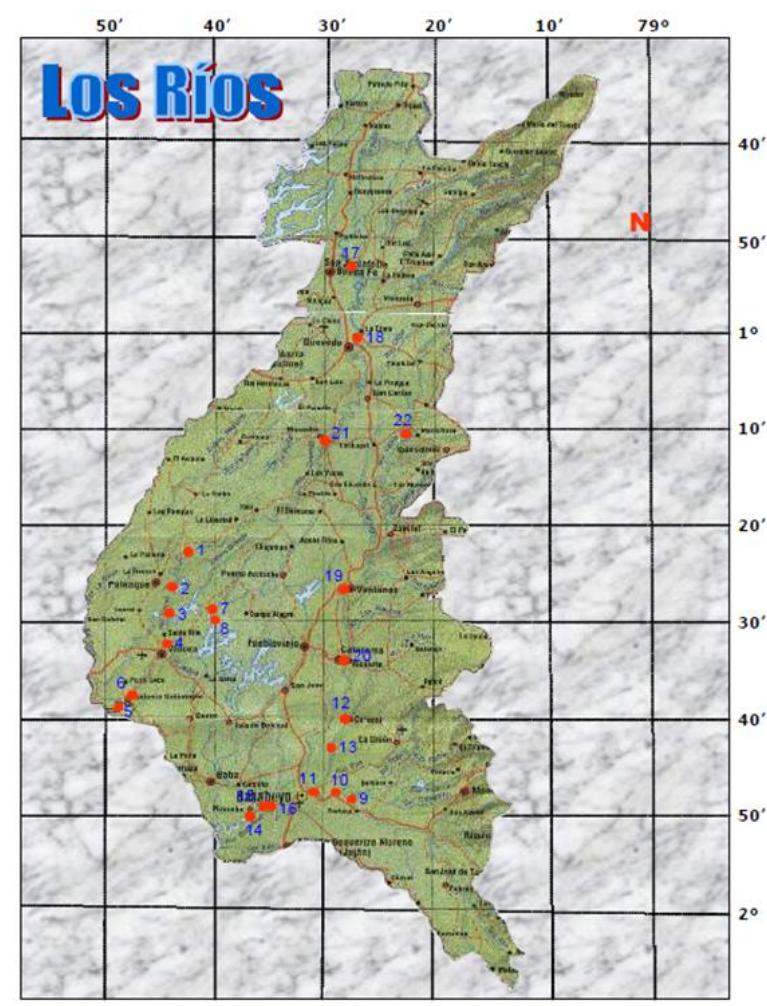

Figura 8. Localización del Humedal Abras de Mantequilla ubicado en la parte inferior izquierda. Fuente: (Quevedo Pino, 2019) 


\section{Subsistema de áreas naturales protegidas para enfrentar delitos ambientales contra la fauna del cantón Quevedo}

Vol. 3, núm. 3., (2019)

Karen Mercedes Barragán Monrroy; Holger Bolívar Alvarado Onofre

\section{Delitos ambientales contra la fauna de la Provincia de Los Ríos, Ecuador}

El cantón Quevedo como es el cantón con más densidad poblacional de la provincia de Los Ríos entonces su significado en el desarrollo económico es importante. La población del cantón fue creciendo en los últimos años, considerándose una población joven, como se detalla en la Figura 9.

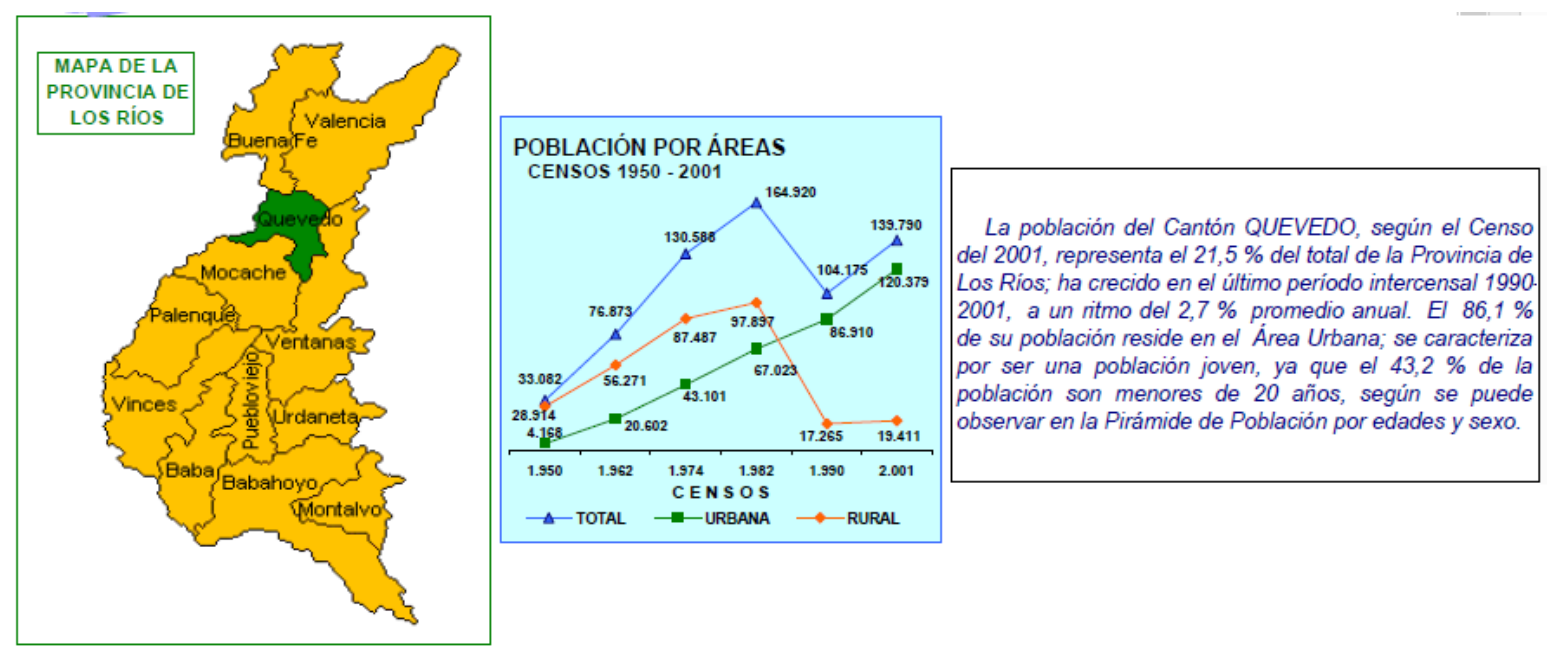

Figura 9. Crecimiento de la población del cantón Quevedo de la provincia Los Ríos, Ecuador

Fuente: (INEC, Cantón Quevedo, 2019)

La mayoría de la población económicamente activa se desenvuelve en actividades de comercio además de agricultura, ganadería, caza, pesca y silvicultura, como se detalla en la Tabla 11. 


\section{Subsistema de áreas naturales protegidas para enfrentar delitos ambientales contra la fauna del cantón Quevedo}

Vol. 3, núm. 3., (2019)

Karen Mercedes Barragán Monrroy; Holger Bolívar Alvarado Onofre

Tabla 11. Grupos ocupacionales y ramas de actividad de la población económicamente activa del cantón Quevedo, provincia de Los Ríos, Ecuador

SEGÚN GRUPOS OCUPACIONALES

\begin{tabular}{|l|c|c|c|}
\hline \multicolumn{1}{|c|}{ GRUPOS DE OCUPACIÓN } & TOTAL & HOMBRES & MUJERES \\
\hline TOTAL & 48.390 & 36.291 & 12.099 \\
MIEMBROS, PROFESIONALES & & & \\
TÉCNICOS & 4.151 & 2.285 & 1.866 \\
EMPLEADOS DE OFICINA & 2.353 & 1.161 & 1.192 \\
TRAB. DE LOS SERVICIOS & 9.301 & 5.786 & 3.515 \\
AGRICULTORES & 3.728 & 3.485 & 243 \\
OPERARIOS Y OPERADORES & & & \\
DE MAQUINARIAS & 11.331 & 10.219 & 1.112 \\
TRAB. NO CALIFICADOS & 12.259 & 9.457 & 2.802 \\
OTROS & 5.267 & 3.898 & 1.369 \\
\hline
\end{tabular}

SEGÚN RAMAS DE ACTIVIDAD

\begin{tabular}{|l|c|c|c|}
\hline \multicolumn{1}{|c|}{ RAMAS DE ACTIVIDAD } & TOTAL & HOMBRES & MUJERES \\
\hline TOTAL & 48.390 & 36.291 & 12.099 \\
& & & \\
AGRICULTURA, GANADERIA & & & \\
CAZA, PESCA, SILVICULTURA & 11.203 & 10.456 & 747 \\
MANUFACTURA & 3.501 & 2.639 & 862 \\
CONSTRUCCIÓN & 3.241 & 3.172 & 69 \\
COMERCIO & 11.573 & 8.330 & 3.243 \\
ENSEÑANZA & 2.483 & 936 & 1.547 \\
OTRAS ACTIVIDADES & 16.389 & 10.758 & 5.631 \\
\hline
\end{tabular}

Fuente: (INEC, Cantón Quevedo, 2019)

Uno de los delitos más graves dentro de un ecosistema es el delito ambiental en función del tráfico y caza ilegal de la fauna. La fauna silvestre ha sido utilizada por milenios por los seres humanos para obtener alimento, pieles y combustible. Las aves son el grupo más utilizado como mascotas dentro de la fauna silvestre (Ministerio-del-Ambiente-del-Ecuador, Informe del trafico ilegal de especies año 2014, 2019).

En el año 2014, se decomisaron 2056 especímenes. Mamíferos (481 individuos), Aves (673 individuos), Reptiles (528 individuos) Anfibios (1 individuo), Peces (1 individuo), Invertebrados (79 individuos) y Plantas (293 individuos) (Ministerio-del-Ambiente-del-Ecuador, Informe del trafico ilegal de especies año 2014, 2019). Esto se puede visualizar en la Figura 10. 
Subsistema de áreas naturales protegidas para enfrentar delitos ambientales contra la fauna del cantón Quevedo

Vol. 3, núm. 3., (2019)

Karen Mercedes Barragán Monrroy; Holger Bolívar Alvarado Onofre

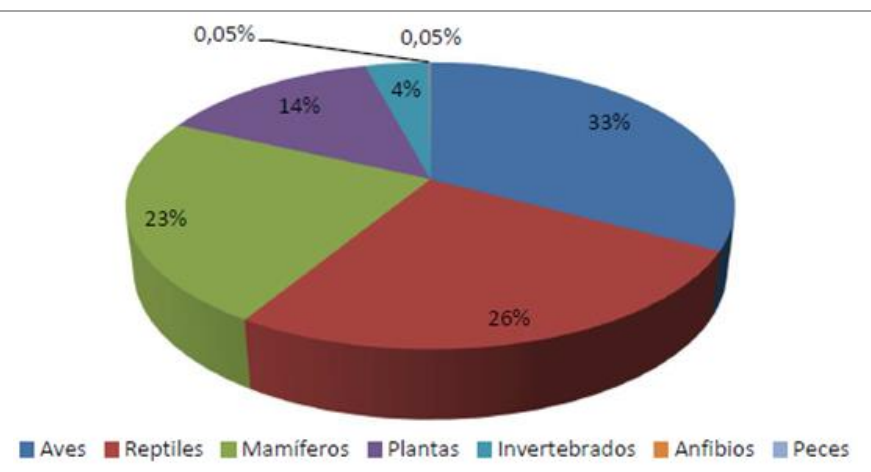

Figura 10. Decomisos por grupos taxonómicos

Fuente: (Ministerio-del-Ambiente-del-Ecuador, Informe del trafico ilegal de especies año 2014, 2019)

También, el número total de libras de carne de monte decomisada es de 1560, para el año 2014, de las cuales 1359 libras son de mamíferos, 17 libras de aves, 64 libras de reptiles y 120 libras de peces (Ministerio-del-Ambiente-del-Ecuador, Informe del trafico ilegal de especies año 2014, 2019), como se detalla en la Figura 11.

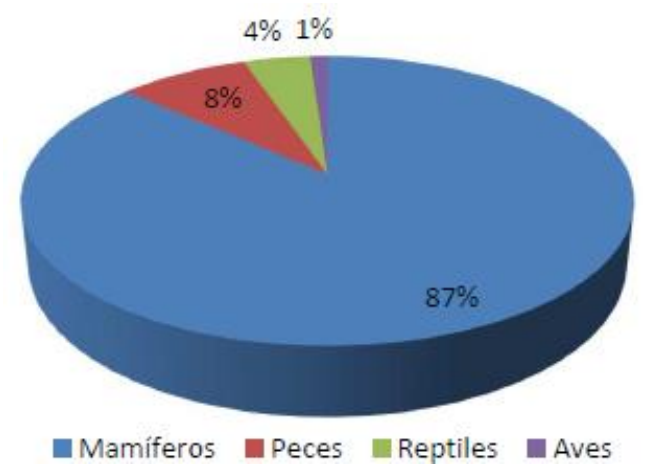

Figura 11. Retenciones de carne de monte para el año 2014 en el Ecuador

Fuente: (Ministerio-del-Ambiente-del-Ecuador, Informe del trafico ilegal de especies año 2014, 2019) 


\section{Subsistema de áreas naturales protegidas para enfrentar delitos ambientales contra la fauna del cantón Quevedo}

Vol. 3, núm. 3., (2019)

Karen Mercedes Barragán Monrroy; Holger Bolívar Alvarado Onofre

Ahora, es necesario determinar los delitos por tráfico de fauna en la provincia de Los Ríos, donde los reptiles fueron los de mayor decomiso de fauna entre las aves y mamíferos. Esto se muestra en la Figura 12. Con respecto a la carne de monte, la provincia de Los Ríos tiene un decomiso para el año 2014 de 33 libras (Ministerio-del-Ambiente-del-Ecuador, Informe del trafico ilegal de especies año 2014, 2019).

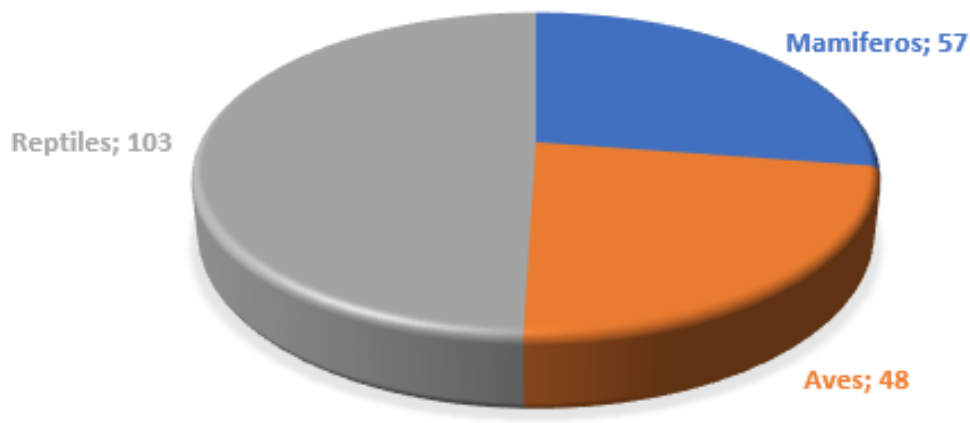

Figura 12. Decomiso de mamíferos por provincia en el año 2014

Fuente: (Ministerio-del-Ambiente-del-Ecuador, Informe del trafico ilegal de especies año 2014, 2019)

Los reptiles decomisados a nivel nacional para el año 2014 se muestran en la Tabla 12. Los mamíferos y avesdecomisados, para el año 2014, que pueden pertenecer a la provincia de Los Ríos se detalla en la Tabla 13. La carne de monte, de mamíferos y aves, que puede provenir de la provincia Los Ríos decomisada, para el año 2014, se visualiza en la Tabla 14. 


\section{Subsistema de áreas naturales protegidas para enfrentar delitos ambientales}

contra la fauna del cantón Quevedo

Vol. 3, núm. 3., (2019)

Karen Mercedes Barragán Monrroy; Holger Bolívar Alvarado Onofre

Tabla 12. Reptiles decomisados a nivel nacional para el año 2014

\begin{tabular}{|l|l|}
\hline \multicolumn{1}{|c|}{ Nombre cientifico } & \multicolumn{1}{c|}{ Nombre común } \\
\hline Chelydra serpentina & Tortuga mordedora \\
\hline Chelonoidis denticulata & Tortuga motelo \\
\hline Boa constrictor & Matacaballo \\
\hline Iguana iguana & Iguana \\
\hline Rhinoclemmys annulata & Tortuga trueno \\
\hline Kinosternon scorpioides & Tortuga pantano \\
\hline Epicrates cenchria & Boa arcoiris \\
\hline Podocnemis expansa & Tortuga charapa \\
\hline Caiman crocodilus & Caimán \\
\hline Melanosuchus niger & Caimán Negro \\
\hline Podocnemis unifilis & Charapa pequeña \\
\hline Rhinoclemmys nasuta & Tortuga pintadilla \\
\hline Chelonia mydas & Tortuga verde \\
\hline Paleosuchus trigonatus & Caimán de frente lisa \\
\hline Trachemys scripta & Tortuga de pantano \\
\hline Crocodylus acutus & Cocodrilo de la costa \\
\hline Dracaena guianensis & Lagartija caimán \\
\hline Emys orbicularis & Tortuga \\
\hline Eunectes murinus & Anaconda \\
\hline Mesoclemmys gibba & Tortuga giba \\
\hline Oxybelis aeneus & Serpiente palo \\
\hline & \\
\hline
\end{tabular}

Fuente: (Ministerio-del-Ambiente-del-Ecuador, Informe del trafico ilegal de especies año 2014, 2019)

Tabla 13. Mamíferos y aves decomisados, para el año 2014, que pueden pertenecer a la provincia de Los Ríos

\begin{tabular}{ccccc}
\hline ESPECIE & ORDEN & FAMILIA & NOMBRE TÉCNICO & NOMBRE \\
\hline MAMIFEROS & Pilosa & Bradypodidae & Bradypusvariegatus & $\begin{array}{c}\text { Perezoso de tres } \\
\text { dedos de }\end{array}$ \\
\hline MAMIFEROS & Didelphimorphia & Didelphidae & Didelphismarsupialis & Zarigüeva \\
\hline MAMIFEROS & Artiodactyla & Tayassuidae & Pecaritaiacu & Pecarí de collar \\
\hline MAMIFEROS & Carnivora & Procyonidae & Potos flavus & Cusumbo \\
\hline MAMIFEROS & Rodentia & Cuniculidae & Guanta de Tierras Bajas & Guanta de \\
\hline MAMIFEROS & Cingulata & Dasypodidae & Dasvpusnovemcinctus & Armadillo de \\
\hline MAMIFEROS & Didelphimorphia & Didelphidae & Caluromysderbianus & Raposa lanuda \\
\hline MAMIFEROS & Carnivora & Procyonidae & Procyon cancrivorus & Oso lavador \\
\hline MAMIFEROS & Artiodactyla & Tayassuidae & Tayassupecari & Pecarí de labio \\
\hline MAMIFEROS & Artiodactyla & Cervidae & Mazama americana & Venado \\
\hline MAMIFEROS & Carnivora & Mustelidae & Lontralongicaudis & Nutria \\
\hline MAMIFEROS & Rodentia & Sciuridae & Sciurusgranatensis & Ardilla de cola \\
\hline
\end{tabular}




\section{Subsistema de áreas naturales protegidas para enfrentar delitos ambientales contra la fauna del cantón Quevedo}

Vol. 3, núm. 3., (2019)

Karen Mercedes Barragán Monrroy; Holger Bolívar Alvarado Onofre

\begin{tabular}{|c|c|c|c|c|}
\hline MAMIFEROS & Carnivora & Mustelidae & Galictisvittata & Hurón \\
\hline AVES & Psittaciformes & Psittacidae & Aratingaervthrogenys & Perico cabeza \\
\hline AVES & Psittaciformes & Psittacidae & Pionusmenstruus & Lora cabeciazul \\
\hline AVES & Psittaciformes & Psittacidae & Amazona farinosa & Lora Amazona \\
\hline AVES & Strigiformes & Tvtonidae & Tyto alba & Lechuza \\
\hline AVES & Gruiformes & Rallidae & Gallinulachloropus & Gallareta \\
\hline AVES & Galliformes & Cracidae & Ortaliservthroptera & Chachalaca \\
\hline AVES & Psittaciformes & Psittacidae & Pionuschalcopterus & Loro \\
\hline AVES & Falconiformes & Accipitridae & Buteomagnirostris & Gavilan \\
\hline AVES & Passeriformes & Icteridae & Diveswarszewiczi & Negro \\
\hline AVES & Psittaciformes & Psittacidae & Forpuscoelestis & Periquito del \\
\hline AVES & Falconiformes & Falconidae & Caracara cheriway & Caracara \\
\hline AVES & Columbiformes & Columbidae & Columbina bucklevi & Tortolita \\
\hline AVES & Ciconiiformes & Ardeidae & Nyctanassaviolacea & Garza nocturna \\
\hline AVES & Anseriformes & Anatidae & Anasbahamensis & Anade \\
\hline AVES & Gruiformes & Aramidae & Aramus guarauna & Carrao \\
\hline AVES & Falconiformes & Accipitridae & Buteobrachyurus & Gavilán \\
\hline AVES & Columbiformes & Columbidae & Claravispretiosa & Tortolito azul \\
\hline AVES & Ciconiiformes & Cathartidae & Coragypsatratus & Gallinazo negro \\
\hline AVES & Anseriformes & Anatidae & Dendrocygna & Pato silbador \\
\hline AVES & Anseriformes & Anatidae & Dendrocygna bicolor & Pato silbador \\
\hline AVES & Ciconiiformes & Ardeidae & Egretta tricolor & Garceta tricolor \\
\hline AVES & Columbiformes & Columbida & Leptotilaverreauxi & Paloma apical \\
\hline AVES & Falconiformes & Accipitridae & Leucopternisoccidentalis & Gavilán \\
\hline AVES & Coraciiformes & Momotidae & Momotusmomota & Momoto \\
\hline AVES & Cuculiformes & Cuculidae & Piaya cayana & Cuco ardilla \\
\hline AVES & Strigiformes & Strigidae & Pulsatrixperspicillata & Búho de \\
\hline AVES & Passeriformes & Icteridae & Sturnellabellicosa & Pastorero \\
\hline AVES & Passeriformes & Thraupidae & Thraupisepiscopus & Tangara azulei \\
\hline
\end{tabular}

Fuente: (Ministerio-del-Ambiente-del-Ecuador, Informe del trafico ilegal de especies año 2014, 2019; Ministerio-del-Ambiente-del-Ecuador, Lista de mamiferos del Ecuador, 2019; Ministeriodel-Ambiente-del-Ecuador, Lista de aves del Ecuador, 2019) 


\section{Subsistema de áreas naturales protegidas para enfrentar delitos ambientales contra la fauna del cantón Quevedo}

Vol. 3, núm. 3., (2019)

Karen Mercedes Barragán Monrroy; Holger Bolívar Alvarado Onofre

Tabla 14. La carne de monte, de mamíferos y aves, que puede provenir de la provincia Los Ríos decomisada, para el año 2014

\begin{tabular}{ccccc}
\hline ESPECIE & ORDEN & FAMILIA & NOMBRE & NOMBRE \\
\hline MAMIFEROS & Artiodactyla & Tayassuidae & Tayassupecari & Pecarí de labio \\
\hline MAMIFEROS & Artiodactyla & Cervidae & Mazama americana & Venado colorado \\
\hline MAMIFEROS & Artiodactyla & Tayassuidae & Pecaritajacu & Sahino \\
\hline MAMIFEROS & Cingulata & Dasypodidae & Dasvpusnovemcinctus & Armadillo 9 \\
\hline AVES & Psittaciformes & Psittacidae & Amazona farinosa & Lora coronilla \\
\hline
\end{tabular}

Fuente: (Ministerio-del-Ambiente-del-Ecuador, Informe del trafico ilegal de especies año 2014, 2019; Ministerio-del-Ambiente-del-Ecuador, Lista de mamiferos del Ecuador, 2019; Ministeriodel-Ambiente-del-Ecuador, Lista de aves del Ecuador, 2019)

Para evitar estos delitos ambientales en contra de la fauna es necesario aplicar alternativas, fuera de las faltas administrativas y penales, que busquen disminuir este tráfico de animales, donde la mayoría es para transformarla en mascotas produciendo un desequilibrio ambiental y ocasionando un trauma en el animal debido al cambio domestico de su habitad.Para ello se pueden crear una serie de estructuras que permitan la preservación de la especie y del sistema donde habita. En la Tabla 15 se puede detallar los usos potenciales para algunas especies amenazadas por el peligro de la extinción.

Tabla 15. Usos potenciales para algunas especies amenazadas del Ecuador

\begin{tabular}{ll}
\hline \multicolumn{1}{c}{ USO } & \multicolumn{1}{c}{ ALTERNATIVA } \\
\hline & $\begin{array}{l}\text { Tradicionalmente algunas especies de mamíferos han sido criados en cautividad } \\
\text { para consumo humano. Algunas de estas especies, como el tapir de costa, } \\
\text { denominada vaca de monte en algunas zonas, podrían ser criadas en cautividad } \\
\text { están en la actualidad prácticamente extinto, y su cría por pobladores locales } \\
\text { puede ayudar a su recuperación bajo el interés gastronómico que pueden despertar } \\
\text { como plato de alta gama. }\end{array}$ \\
\hline $\begin{array}{l}\text { Instalaciones comómico } \\
\text { centros temáticos y y y } \\
\text { recreativos. }\end{array}$ & $\begin{array}{l}\text { Estos centros podrían ser válidos para distintas especies. No obstante, algunas } \\
\text { especies como caimanes y cocodrilos, en peligro crítico algunas de ellas en la } \\
\text { costa ecuatoriana, podrían ser recuperados en zonas pantanosas privadas que, }\end{array}$ \\
\hline
\end{tabular}




\section{Subsistema de áreas naturales protegidas para enfrentar delitos ambientales contra la fauna del cantón Quevedo}

Vol. 3, núm. 3., (2019)

Karen Mercedes Barragán Monrroy; Holger Bolívar Alvarado Onofre

\begin{tabular}{ll}
\hline & como alternativa a la desecación o en la conversión en arrozales podrían mantener \\
poblaciones de estas especies convirtiéndose en centros turísticos que se han \\
mostrado muy eficientes en numerosos lugares. \\
\hline Entre los vertebrados terrestres utilizados por las comunidades de cazadores \\
locales en el neotrópico se han identificado sobre 15 especies de mamíferos \\
(ungulados y primates principalmente), más de 30 especies de aves y algunos \\
reptiles tales como tortugas, iguanas y cocodrilos. Se debe aplicar programas de \\
reintroducción de estas especies que podrían ser financiados por la iniciativa \\
privada ante el eventual beneficio que le seguiría.
\end{tabular}

Fuente: (Sánchez Tortosa \& Shiguango Párraga, 2015)

Normativa legal para la protección de la fauna silvestre en el Ecuador

En el Ecuador existen diversas normas, leyes u ordenanzas en pro de la defensa de la biodiversidad. Las principales leyes de la nación en favor de la protección de la fauna silvestre es la Constitución de la República del Ecuador, Ley de Gestión Ambiental, CódigoOrgánico del Ambiente, Ley Forestal y Conservación de Áreas Naturales y Vida Silvestre, Código Orgánico de Organización Territorial y Código Orgánico Integral Penal.

Constitución de la República de Ecuador frente a la fauna silvestre

Dentro de la carta magna se encuentra reflejados los artículos 3, 14, 66, 71, 73, 261, 264, 397, 398, 405, 406, 409, 411 y 414 que plantean la protección del ecosistema y la biodiversidad presente en el territorio nacional.

Que, el numeral 7 del artículo 3 de la Constitución de la República del Ecuador establece como deber primordial del Estado ecuatoriano la protección del patrimonio natural y cultural del país; 


\section{Subsistema de áreas naturales protegidas para enfrentar delitos ambientales contra la fauna del cantón Quevedo}

Vol. 3, núm. 3., (2019)

Karen Mercedes Barragán Monrroy; Holger Bolívar Alvarado Onofre

Art. 14.- Se reconoce que la población tiene derecho a vivir en un ambiente sano y ecológicamente equilibrado y el buen vivir. Se declara de interés público la preservación del ambiente, de los ecosistemas, la biodiversidad y la integridad del patrimonio genético del país, la prevención del daño ambiental y la recuperación de los espacios naturales degradados. (Asamblea-Constituyente-CRE, 2008)

Que, el numeral 27 del artículo 66 de la Constitución de la República del Ecuador, establece que se reconoce y garantizará a las personas el derecho a vivir en un ambiente sano, ecológicamente equilibrado, libre de contaminación y en armonía con la naturaleza;

Art. 71.- La naturaleza tiene el derecho a que se respete integralmente su existencia y el mantenimiento y regeneración de sus ciclos vitales, estructuras, funciones y procesos evolutivos. Toda persona, comunidad, pueblo o nacionalidad podrá exigir a la autoridad pública el cumplimiento de los derechos de la naturaleza. El estado incentivará a las personas naturales y jurídicas, y a los colectivos, para que protejan la naturaleza, y promoverá el respeto a todos los elementos que forma un ecosistema. (Asamblea-Constituyente-CRE, 2008)

Art. 73.- El Estado es la autoridad que aplicará las medidas de precaución y restricción para las actividades que pueden conducir a la extinción de especies, la destrucción de ecosistemas o la alteración permanente de los ciclos naturales. Se prohíbe la introducción de organismos y material orgánico e inorgánico que puedan alterar de manera definitiva el patrimonio genético nacional. (Asamblea-Constituyente-CRE, 2008)

Que, los numerales 1 y 2 del artículo 264 de la Constitución señala que es competencia exclusiva de los gobiernos cantonales, las siguientes: 


\section{Subsistema de áreas naturales protegidas para enfrentar delitos ambientales contra la fauna del cantón Quevedo}

Vol. 3, núm. 3., (2019)

Karen Mercedes Barragán Monrroy; Holger Bolívar Alvarado Onofre

"1. Planificar el desarrollo cantonal y formular los correspondientes planes de ordenamiento territorial, de manera articulada con la planificación nacional, regional, provincial y parroquial, con el fin de regular el uso y la ocupación del suelo urbano y rural"; "2. Ejercer el control sobre el uso y ocupación del suelo en el cantón". (AsambleaConstituyente-CRE, 2008, pág. 130)

El artículo 261 de la Constitución de la República del Ecuador le otorga potestad y competencia exclusiva al Estado Central sobre: las áreas naturales protegidas, los recursos naturales, los recursos energéticos; minerales, hidrocarburos, hídricos, biodiversidad y recursos forestales(Asamblea-Constituyente-CRE, 2008).

Que, el artículo 397 de la Constitución de la República del Ecuador establece que:

“En caso de daños ambientales el Estado actuará de manera inmediata y subsidiaria para garantizar la salud y la restauración de los ecosistemas. Además de la sanción correspondiente, el Estado repetirá contra el operador de la actividad que produjera el daño las obligaciones que conlleve la reparación integral, en las condiciones y con los procedimientos que la ley establezca.La responsabilidad también recaerá sobre las servidoras o servidores responsables de realizar el control ambiental. Para garantizar el derecho individual y colectivo a vivir en un ambiente sano y ecológicamente equilibrado, el Estado se compromete a:

1. Permitir a cualquier persona natural o jurídica, colectividad o grupo humano, ejercer las acciones legales y acudir a los órganos judiciales y administrativos, sin perjuicio de su interés directo, para obtener de ellos la tutela efectiva en materia ambiental, incluyendo la 


\section{Subsistema de áreas naturales protegidas para enfrentar delitos ambientales contra la fauna del cantón Quevedo}

Vol. 3, núm. 3., (2019)

Karen Mercedes Barragán Monrroy; Holger Bolívar Alvarado Onofre

posibilidad de solicitar medidas cautelares que permitan cesar la amenaza o el daño ambiental materia de litigio. La carga de la prueba sobre la inexistencia de daño potencial o real recaerá sobre el gestor de la actividad o el demandado. 2. Establecer mecanismos efectivos de prevención y control de la contaminación ambiental, de recuperación de espacios naturales degradados y de manejo sustentable de los recursos naturales. 3. Regular la producción, importación, distribución, uso y disposición final de materiales tóxicos y peligrosos para las personas o el ambiente. 4. Asegurar la intangibilidad de las áreas naturales protegidas, de tal forma que se garantice la conservación de la biodiversidad y el mantenimiento de las funciones ecológicas de los ecosistemas. El manejo y administración de las áreas naturales protegidas estará a cargo del Estado. 5.Establecer un sistema nacional de prevención, gestión de riesgos y desastres naturales, basado en los principios de inmediatez, eficiencia, precaución, responsabilidad y solidaridad". (AsambleaConstituyente-CRE, 2008, pág. 178)

Que, el artículo 398 de la Constitución, señala que la comunidad debe estar informada sobre las decisiones o autorizaciones del estado que puedan afectar el ambiente. También, el artículo 405 manifiesta que el sistema nacional de áreas protegidas es el encargado de garantizar la conservación de la biodiversidad y el mantenimiento de las funciones ecológicas. El sistema se integrará por los subsistemas estatal, autónomo descentralizado, comunitario y privado, y su rectoría y regulación será ejercida por el Estado. (Asamblea-Constituyente-CRE, 2008)

Es importante resaltar el artículo 406 el cual expresa: 


\section{Subsistema de áreas naturales protegidas para enfrentar delitos ambientales contra la fauna del cantón Quevedo}

Vol. 3, núm. 3., (2019)

Karen Mercedes Barragán Monrroy; Holger Bolívar Alvarado Onofre

"El Estado regulará la conservación, manejo y uso sustentable, recuperación, y limitaciones de dominio de los ecosistemas frágiles y amenazados, entre otros, los páramos, humedales, bosques nublados, bosques tropicales secos y húmedos y manglares, ecosistemas marinos y marinos-costeros”. (Asamblea-Constituyente-CRE, 2008, pág. 180)

Además, que el artículo 409, 411 y 414 de la Constitución, establecen:

“Es de interés público y prioridad nacional la conservación del suelo, en especial su capa fértil. Se establecerá un marco normativo para su protección y uso sustentable que prevenga su degradación, en particular la provocada por la contaminación, la desertificación y la erosión”.

El Estado garantizará la conservación, recuperación y manejo integral de los recursos hídricos, cuencas hidrográficas y caudales ecológicos asociados al ciclo hidrológico. Se regulará toda actividad que pueda afectar la calidad y cantidad de agua, y el equilibrio de los ecosistemas, en especial en las fuentes y zonas de recarga de agua. ”;

“El Estado adoptará medidas adecuadas y transversales para la mitigación del cambio climático, mediante la limitación de las emisiones de gases de efecto invernadero, de la deforestación y de la contaminación atmosférica; tomará medidas para la conservación de los bosques y la vegetación, y protegerá a la población en riesgo”. (AsambleaConstituyente-CRE, 2008, págs. 181-182)

Ley Forestal y de Conservación de Áreas Naturales y Vida Silvestre. 


\section{Subsistema de áreas naturales protegidas para enfrentar delitos ambientales contra la fauna del cantón Quevedo}

Vol. 3, núm. 3., (2019)

Karen Mercedes Barragán Monrroy; Holger Bolívar Alvarado Onofre

Esta ley radica en la importancia de los ecosistemas, como los bosques, como también las flora y fauna que existen en estos paisajes para el desarrollo íntegro y sostenible del planeta. De esta ley se toman artículos de importancia y relevancia a la investigación realizada, como son los artículos 9, 10, 11, 12, 28 у 66.

El CAPÍTULO IV trata de las Tierras Forestales y de los Bosques de Propiedad Privada a través de los siguientes artículos:

“Art. 9.- Entiéndase por tierras forestales aquellas que, por sus condiciones naturales, ubicación, o por no ser aptas para la explotación agropecuaria, deben ser destinadas al cultivo de especies maderables y arbustivas, a la conservación de la vegetación protectora, inclusive la herbácea y la que así se considere mediante estudios de clasificación de suelos, de conformidad con los requerimientos de interés público y de conservación del medio ambiente.

Art. 10.- El Estado garantiza el derecho de propiedad privada sobre las tierras forestales y los bosques de dominio privado, con las limitaciones establecidas en la Constitución y las Leyes. Tratándose de bosques naturales, en tierras de exclusiva aptitud forestal, el propietario deberá conservarlos y manejarlos con sujeción a las exigencias técnicas que establezcan los reglamentos de esta Ley.

Art. 11.- Las tierras exclusivamente forestales o de aptitud forestal de dominio privado que carezcan de bosques serán obligatoriamente reforestadas, estableciendo bosques protectores o productores, en el plazo y con sujeción a los planes que el Ministerio del Ambiente les señale. Si los respectivos propietarios no cumplieren con esta disposición, 


\section{Subsistema de áreas naturales protegidas para enfrentar delitos ambientales contra la fauna del cantón Quevedo}

Vol. 3, núm. 3., (2019)

Karen Mercedes Barragán Monrroy; Holger Bolívar Alvarado Onofre tales tierras podrán ser expropiadas, revertidas o extinguido el derecho de dominio, previo informe técnico, sobre el cumplimiento de estos fines.

Art. 12.- Los propietarios de tierras forestales, especialmente las asociaciones, cooperativas, comunas y otras entidades constituidas por agricultores directos, recibirán del Estado asistencia técnica y crediticia para el establecimiento y manejo de nuevos bosques”.(Congreso-Nacional-LFCANVS, 2004, pág. 3)

En el CAPITULO VI se basa en la producción y aprovechamiento forestal, donde se toma en cuenta el siguiente artículo

"Art. 28.- Los contratos de aprovechamiento forestal de los bosques estatales de producción permanente, no confieren a los beneficiarios la propiedad ni otro derecho real sobre las tierras en que se encuentren dichos bosques". (Congreso-Nacional-LFCANVS, 2004, págs. 5-6)

Dentro de esta ley se encuentra la relevancia de las áreas naturales y de las flora y fauna silvestre enmarcado en el TITULO II y a su vez el CAPÍTULO I sobre el patrimonio nacional de las áreas naturales, donde se refleja

“Art. 66.- El patrimonio de áreas naturales del Estado se halla constituido por el conjunto de áreas silvestres que se destacan por su valor protector, científico, escénico, educacional, turístico y recreacional, por su flora y fauna, o porque constituyen ecosistemas que contribuyen a mantener el equilibrio del medio ambiente".(Congreso-Nacional-LFCANVS, 2004, pág. 10) 


\section{Subsistema de áreas naturales protegidas para enfrentar delitos ambientales contra la fauna del cantón Quevedo}

Vol. 3, núm. 3., (2019)

Karen Mercedes Barragán Monrroy; Holger Bolívar Alvarado Onofre

Código Orgánico Integral Penal frente a los delitos ambientales.

Los delitos ambientales producidos por una persona o grupo de persona debido a interés propios deben ser evaluados y penalizados, administrativa y judicialmente, por lo que este código manifiesta algunos artículos que pueden devengar en dichas sanciones, dependiendo de la gravedad cometida al ecosistema y biodiversidad presente en ella.

El CAPITULO IV el cual se basa en los delitos contra el ambiente y la naturaleza o Pacha Mama, específicamente en la SECCIÓN PRIMERA sobre los Delitos contra la Biodiversidad establece los artículos 245, 246 y 247 en concordancia con la investigación realizada.

"Art. 245.- Invasión de áreas de importancia ecológica. La persona que invada las áreas del Sistema Nacional de ÁreasProtegidas o ecosistemas frágiles, será sancionada con pena privativa de libertad de uno a tres años.

Se aplicará el máximo de la pena prevista cuando:

1. Como consecuencia de la invasión, se causen daños graves a la biodiversidad y recursos naturales.

2. Se promueva, financie o dirija la invasión aprovechándose de la gente con engaño o falsas promesas.

Art. 246.- Incendios forestales y de vegetación. La persona que provoque directa o indirectamente incendios o instigue la comisión de tales actos, en bosques nativos o plantados o páramos, será sancionada con pena privativa de libertad de uno a tres años. 


\section{Subsistema de áreas naturales protegidas para enfrentar delitos ambientales contra la fauna del cantón Quevedo}

Vol. 3, núm. 3., (2019)

Karen Mercedes Barragán Monrroy; Holger Bolívar Alvarado Onofre Se exceptúan las quemas agrícolas o domésticas realizadas por las comunidades o pequeños agricultores dentro de su territorio. Si estas quemas se vuelven incontrolables y causan incendios forestales, la persona será sancionada por delito culposo con pena privativa de libertad de tres a seis meses.

Si como consecuencia de este delito se produce la muerte de una o más personas, se sancionará con pena privativa de libertad de trece a dieciséis años.

Art. 247.- Delitos contra la flora y fauna silvestres.- La persona que cace, pesque, capture, recolecte, extraiga, tenga, transporte, trafique, se beneficie, permute o comercialice, especímenes o sus partes, sus elementos constitutivos, productos y derivados, de flora o fauna silvestre terrestre, marina o acuática, de especies amenazadas, en peligro de extinción y migratorias, listadas a nivel nacional por la Autoridad Ambiental Nacional así como instrumentos o tratados internacionales ratificados por el Estado, será sancionada con pena privativa de libertad de uno a tres años.

Se aplicará el máximo de la pena prevista si concurre alguna de las siguientes circunstancias:

1. El hecho se cometa en período o zona de producción de semilla o de reproducción o de incubación, anidación, parto, crianza o crecimiento de las especies.

2. El hecho se realice dentro del Sistema Nacional de Áreas Protegidas.

Se exceptúan de la presente disposición, únicamente la cacería, la pesca o captura por subsistencia, las prácticas de medicina tradicional, así como el uso y consumo doméstico 


\section{Subsistema de áreas naturales protegidas para enfrentar delitos ambientales contra la fauna del cantón Quevedo}

Vol. 3, núm. 3., (2019)

Karen Mercedes Barragán Monrroy; Holger Bolívar Alvarado Onofre

de la madera realizada por las comunidades en sus territorios, cuyos fines no sean comerciales ni de lucro, los cuales deberán ser coordinados con la Autoridad Ambiental Nacional”.(Asamblea-Nacional-de-la-República-de-Ecuador-COIP, 2019, págs. 84-85)

\section{Código Orgánico Ambiental}

Dentro de este código se busca los artículos que reflejen la protección del medio ambiente y de las especies que hacen vida dentro de estas áreas. El CAPÍTULO II que plantea la importancia del Sistema Nacional de Áreas Protegidas en el siguiente artículo

“Art. 38.- Objetivos. Las áreas naturales incorporadas al Sistema Nacional de Areas Protegidas, cumplirán con los siguientes objetivos:

1. Conservar y usar de forma sostenible la biodiversidad a nivel de ecosistemas, especies y recursos genéticos y sus derivados, así como las funciones ecológicas y los servicios ambientales;

2. Proteger muestras representativas con valores singulares, complementarios y vulnerables de ecosistemas terrestres, insulares, dulceacuícolas, marinos y marino-costeros;

3. Proteger las especies de vida silvestre y variedades silvestres de especies cultivadas, así como fomentar su recuperación, con especial énfasis en las nativas, endémicas, amenazadas y migratorias;

4. Establecer valores de conservación sobre los cuales se priorizará su gestión; 


\section{Subsistema de áreas naturales protegidas para enfrentar delitos ambientales contra la fauna del cantón Quevedo}

Vol. 3, núm. 3., (2019)

Karen Mercedes Barragán Monrroy; Holger Bolívar Alvarado Onofre

5. Mantener la dinámica hidrológica de las cuencas hidrográficas y proteger los cuerpos de aguas superficiales y subterráneas;

6. Garantizar la generación de bienes y servicios ambientales provistos por los ecosistemas e integrarlos a los modelos territoriales definidos por los Gobiernos Autónomos Descentralizados;

7. Proteger las bellezas escénicas y paisajísticas, sitios de importancia histórica, arqueológica o paleontológica, así como las formaciones geológicas;

8. Respetar, promover y mantener las manifestaciones culturales, el conocimiento tradicional, colectivo y saber ancestral de las comunas, comunidades, pueblos y nacionalidades e integrarlas al manejo de las áreas protegidas;

9. Promover el bioconocimiento y la valoración de los servicios ecosistémicos articulados con el talento humano, la investigación, la tecnología y la innovación, para los cual se estimulará la participación del sector académico público, privado, mixto y comunitario;

10. Impulsar alternativas de recreación y turismo sostenible, así como de educación e interpretación ambiental;

11. Garantizar la conectividad funcional de los ecosistemas en los paisajes terrestres, marinos y marino-costeros; $y$, 


\section{Subsistema de áreas naturales protegidas para enfrentar delitos ambientales contra la fauna del cantón Quevedo}

Vol. 3, núm. 3., (2019)

Karen Mercedes Barragán Monrroy; Holger Bolívar Alvarado Onofre

12. Aportar a la adaptación y mitigación del cambio climático mediante los mecanismos previstos en este Código".(Asamblea-Nacional-de-la-República-de-Ecuador-COA, 2019, págs. 22-23)

En este mismo capítulo se plantea lo siguiente:

“Art. 47.- De la delegación. La Autoridad Ambiental Nacional determinará los criterios para la delegación de la administración de las áreas naturales que conforman el subsistema estatal y el subsistema autónomo descentralizado, siempre y cuando se garantice el cumplimiento de sus objetivos, de conformidad con las disposiciones constitucionales". (Asamblea-Nacional-de-la-República-de-Ecuador-COA, 2019, pág. 24)

También este código en su CAPÍTULO II referente al plan de manejo costero integrado específica en el TÍTULO IV de los Recursos Marinos, plantea el siguiente artículo

“Art. 277.- De la gestión sobre la biodiversidad, pesquerías y acuicultura marina. La Autoridad Ambiental Nacional con las demás autoridades competentes serán las encargadas de coordinar la evaluación, monitoreo y cálculo del impacto de la acidificación oceánica en el desarrollo productivo, dirigida a la mitigación con prioridad en:

1. El equilibrio de los ecosistemas marinos y su capacidad de resiliencia, con especial énfasis en zonas de alta diversidad, ecosistemas sensibles y áreas naturales protegidas;

2. Especies de interés pesquero y con potencial de explotación pesquera, la alteración de su biología, migración, distribución, pérdida poblacional y otros factores que pudieran identificarse; $y$, 


\section{Subsistema de áreas naturales protegidas para enfrentar delitos ambientales contra la fauna del cantón Quevedo}

Vol. 3, núm. 3., (2019)

Karen Mercedes Barragán Monrroy; Holger Bolívar Alvarado Onofre

3. Especies utilizadas y con potencial de uso en acuicultura y maricultura que pudieran verse afectadas”.(Asamblea-Nacional-de-la-República-de-Ecuador-COA, 2019, pág. 72)

Código Orgánico de Organización Territorial, Autonomía y Descentralización.

En el literal d) del artículo 4 de este código referente al CAPÍTULO I sobre los Principios Generales se basa

“(...) d) La recuperación y conservación de la naturaleza y el mantenimiento de un ambiente sostenible y sustentable; (...)”. (Asamblea-Nacional-de-la-República-deEcuador-COOTAD, 2019, pág. 10)

Dentro de este código está el CAPÍTULO III que se refiere al Gobierno Autónomo Descentralizado Municipal en su SECCIÓN PRIMERA que establece a la Naturaleza Jurídica Sede y Funciones, a través de los literales a) y k) del artículo 54 donde las funciones de los gobiernos municipales son las siguientes

“a) Promover el desarrollo sustentable de su circunscripción territorial cantonal, para garantizar la realización del buen vivir a través de la implementación de políticas públicas cantonales, en el marco de sus competencias constitucionales y legales”; y, “k) Regular, prevenir y controlar la contaminación ambiental en el territorio cantonal de manera articulada con las políticas ambientales nacionales". (Asamblea-Nacional-de-laRepública-de-Ecuador-COOTAD, 2019, págs. 36-37) 


\section{Subsistema de áreas naturales protegidas para enfrentar delitos ambientales contra la fauna del cantón Quevedo}

Vol. 3, núm. 3., (2019)

Karen Mercedes Barragán Monrroy; Holger Bolívar Alvarado Onofre

Instrumentos internacionales sobre medio ambiente y desarrollo sostenible.

La comunidad global en los últimos años ha tenido una ferviente preocupación por el derecho ambiental que se ha visto vulnerable debido al cambio y desarrollo exponencial del progreso del hombre sin medir las consecuencias de dichos actos. Esto ha producido notablemente un cambio climático que altera todos los ecosistemas y biodiversidad presente en las áreas naturales del planeta.

Para frenar este avance voraz de la globalización y sus instrumentos es necesario la aplicación de diferentes tratados internacionales donde sus objetivos están enmarcados en las leyes y normas sobre protección del medio ambiente de los países. Ecuador no escapa de su preocupación sobre estos acontecimientos y ha buscado salvaguardar su ricos medios ambientes y especies presentes en sus espacios naturales.

Los tratados internacionales de relevancia con este artículo científico se representan en la Tabla 16. 


\section{Subsistema de áreas naturales protegidas para enfrentar delitos ambientales contra la fauna del cantón Quevedo}

Vol. 3, núm. 3., (2019)

Karen Mercedes Barragán Monrroy; Holger Bolívar Alvarado Onofre

Tabla 16. Tratados internacionales sobre medio ambiente y desarrollo sostenible

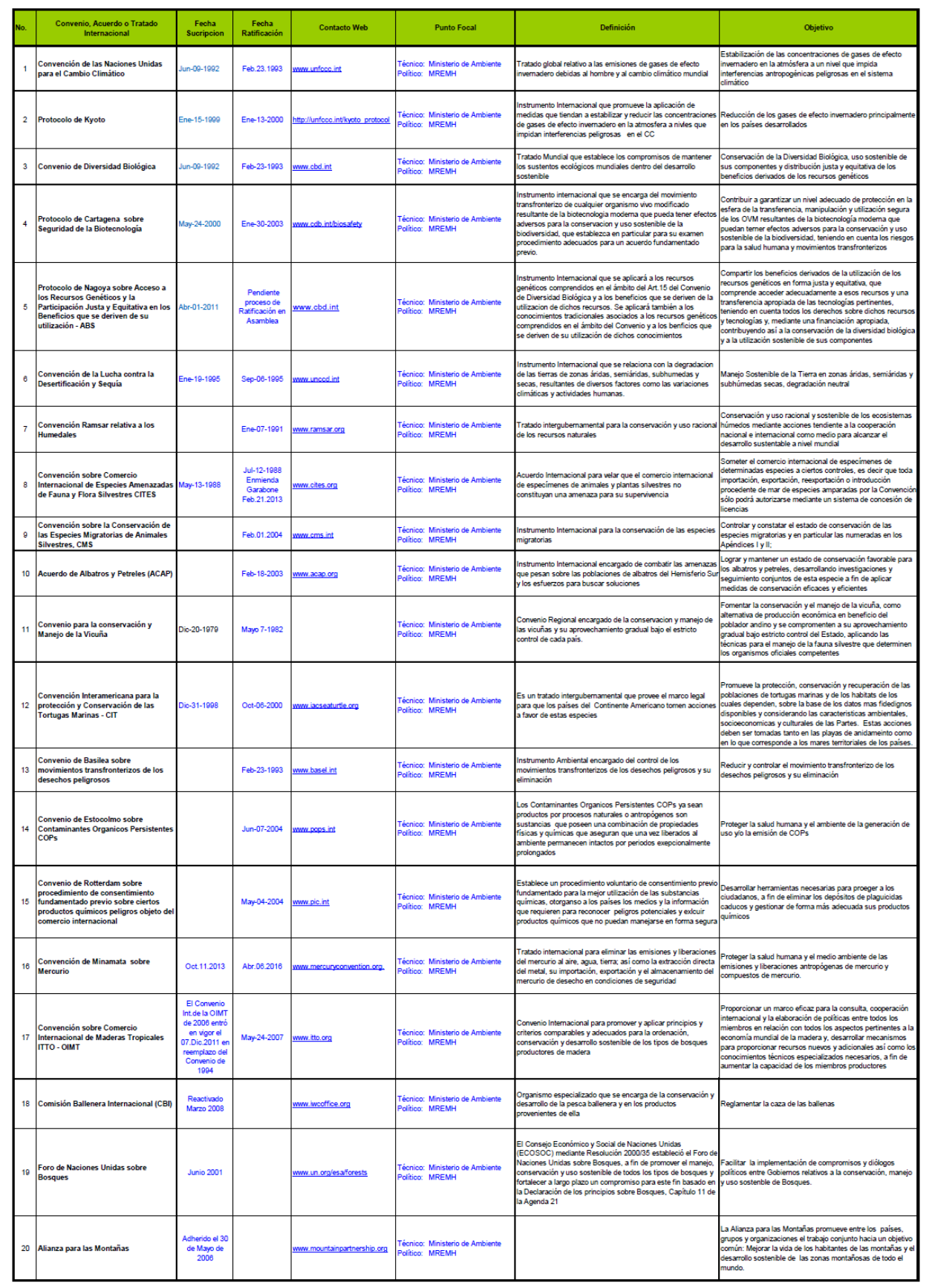

Fuente: (Ministerio-del-Ambiente-del-Ecuador, Tratados multilaterales sobre el medio ambiente y desarrollo sostenible, 2019) 


\section{Subsistema de áreas naturales protegidas para enfrentar delitos ambientales contra la fauna del cantón Quevedo}

Vol. 3, núm. 3., (2019)

Karen Mercedes Barragán Monrroy; Holger Bolívar Alvarado Onofre

\section{Discusión y conclusiones.}

El crecimiento de las sociedades está enmarcado en muchas aristas, una de ellas es el crecimiento demográfico. Esto ha permitido que la mano del hombre llegue a espacios naturales permitiendo la tela y quema de bosques y espacios verdes, sufriendo la flora y fauna del lugar. Con este crecimiento demográfico se viene el aumento de infraestructura como vías y edificios. Todo esto genera un impacto ambiental.

Este impacto ambiental es calculado a través de ecuaciones matemáticas y tiene como base el impacto que generan las industrias y la contaminación del aires, suelo, agua, sonora y visual con el fin de poder ejecutar una penalización con carácter administrativo o jurisdiccional. Las sociedades deben controlar su paso y crecimiento ya que esto genera el cambio climático que sufre el planeta. Es necesario poder controlar todos estos parámetros con el fin de que la biodiversidad y el ecosistema tengan menor impacto posible de este crecimiento voraz.

En el Ecuador, existe una gran biodiversidad en su ambiente y es debido a la multiformas geográficas que existen dentro de su territorio. Desde climas templados, pasando por climas húmedos, áridos y de costa. Todos estos ambientes hacen que la flora y fauna sea bastante numerosa y considerada a nivel mundial como una de las más abundantes del planeta.Es por ello, que es importante poder proteger estas áreas naturales con el fin de disminuir el impacto ambiental generado por la mano del hombre.

El organismo dedicado a este tipo de protección es el Sistema Nacional de Áreas Protegidas (SNAP), la cual consiste enabarcar todos aquellos espacios que puedan servir para el desarrollo sustentable y sostenible de la sociedad. En ellos hay cuencas hidrográficas y 


\section{Subsistema de áreas naturales protegidas para enfrentar delitos ambientales contra la fauna del cantón Quevedo}

Vol. 3, núm. 3., (2019)

Karen Mercedes Barragán Monrroy; Holger Bolívar Alvarado Onofre

vegetación que permite obtener una mejor calidad de vida. Dentro de los SNAP hay una variedad de parques nacionales, monumentos naturales, reservas biológicas, reservas naturales, entre otros espacios que pueden ser de vital importancia para subsistencia de los seres vivos que puedan habitar dentro de ellos.

En la provincia de Los Ríos no existe un espacio que pueda estar dentro del SNAP. Existe un área natural denominada Humedal Abras de Mantequilla donde existe una gran variedad de aves y fauna característico de esa región.Este humedal pertenece a los cantones Vinces, Babahoyo y Pueblo Viejo. En el cantón Quevedo no existe un área que esta registrada en los sistemas gubernamentales encargados del medio ambiente ecuatoriano, pero no se excluye de que posea dentro de sus límites geográficos una flora y fauna importante.

Los delitos ambientales que pueden estar en contra de la fauna es el tráfico de mamíferos, reptiles y aves. Los datos encontrados provienen de los animales decomisados vivos, pero también como carne de monte, a nivel nacional y a nivel de la provincia de Los Ríos. El cantón Quevedo no escapa de estas estadísticas ya que muchos de estos animales que estaban en cautiverio son utilizados como mascotas domésticas y como alimento en las mesas de los cantoneses, generando un gran impacto ambiental en la zona, pero sobre todo un impacto en el animal debido al cambio de su habitad. Se puede plantear una serie de alternativas para disminuir esta actividad, entre ellas la creación de espacios para la crianza de animales destinados a ser alimentos para los ciudadanos a través de granjas y la creación de parques temáticos o zoológicos que muestren los animales autóctonos de la región. Con ello podría servir de disminuir la caza y aumentar la biodiversidad en la región. 


\section{Subsistema de áreas naturales protegidas para enfrentar delitos ambientales contra la fauna del cantón Quevedo}

Vol. 3, núm. 3., (2019)

Karen Mercedes Barragán Monrroy; Holger Bolívar Alvarado Onofre

Existen los preceptos jurídicos para la reparación integral de la fauna silvestre, garantizando su protección de manera adecuada y eficaz, es decir que la naturaleza esté protegida haciendo prevalecer los Derechos establecidos dentro de la Constitución de la República del Ecuador y Tratados Internacionales acogidos por nuestra legislación, la Carta Magna enfatiza el respeto integral a sus ciclos vitales, procesos evolutivos y su protección, además el Ecuador tiene una gran biodiversidad que debe ser salvaguardada de manera directa e inmediata controlando que las personas no realicen actividades ilegales en contra de la fauna silvestre, se establecieron las acciones de protección del subsistema de áreas naturales y los mecanismos para ejecutar estas medidas reparadoras en función del medio ambiente para su preservación.

\section{Bibliografía.}

Asamblea-Constituyente-CRE. (2008). Constitución de la República de Ecuador. Quito, Ecuador.

Asamblea-Nacional-de-la-República-de-Ecuador-COA. (30 de Septiembre de 2019). Código Orgánico Ambiental. Obtenido de http://www.competencias.gob.ec/wpcontent/uploads/2017/06/05NOR2017-COA.pdf

Asamblea-Nacional-de-la-República-de-Ecuador-COIP. (30 de Septiembre de 2019). Código Orgánico Integral Penal. Obtenido de https://www.defensa.gob.ec/wpcontent/uploads/downloads/2018/03/COIP_feb2018.pdf

Asamblea-Nacional-de-la-República-de-Ecuador-COOTAD. (30 de Septiembre de 2019). Código Orgánico de Organización Territorial, Autonomía y Descentralización. Obtenido de https://www.defensa.gob.ec/wpcontent/uploads/downloads/2016/01/dic15_CODIGOORGANICO-DEORGANIZACION-TERRITORIAL-COOTAD.pdf

Bacusoy, A. R., Díaz, W. R., \& Gavilánez, J. L. (2019). Estrategias de seguridad ambiental frente a los cambios climáticos en base a los incendios forestales. RECIMUNDO, 3(1), 997-1023.

Baquero Correa, W. E. (2015). El esquema normativo ecuatoriano aplicable a la evaluación de impacto ambiental; materializa el principio de prevención? enfoque en areas naturales 


\section{Subsistema de áreas naturales protegidas para enfrentar delitos ambientales contra la fauna del cantón Quevedo}

Vol. 3, núm. 3., (2019)

Karen Mercedes Barragán Monrroy; Holger Bolívar Alvarado Onofre

protegidas. Quito, Ecuador: TRabajo de Grado - Universidad San Francisco de Quito, Colegio de Jurisprudencia.

Congreso-Nacional-LFCANVS. (2004). LEY FORESTAL Y DE CONSERVACION DE AREAS NATURALES Y VIDA SILVESTRE. Quito, Ecuador.

De la Cuesta Arzamendi, J. L. (2009). Cuestiones dogmáticas relativas al delito de contaminación ambiental. Revista penal, 4(4), 30-41.

De Santis, P. R. (2018). Obtención de un índice de contaminación ambiental producto de la actividad petrolera en distintos escenarios de la Amazonía ecuatoriana por medio de análisis de componentes principales. RECIAMUC, 2(1), 575-597.

Fernández Moreno, Y. (2008). ¿ Por qué estudiar las percepciones ambientales?: Una revisión de la literatura mexicana con énfasis en Áreas Naturales Protegidas. Espiral (Guadalajara), 15(43), 179-202.

García Sanz, J. (2008). El delito de contaminación ambiental. ANALES DE LA FACULTAD DE DERECHO, Universidad de La Laguna, 25; pp. 117-137.

García-Frapolli, E., \& Toledo, V. M. (2008). Evaluación de sistemas socioecológicos en áreas protegidas: un instrumento desde la economía ecológica. Argumentos (México, DF), 21(56), 103-116.

Goicochea, Z. I. (2011). Valoración económica del patrimonio natural: las áreas naturales protegidas. Espacio y desarrollo, (23), 131-154.

Hernández, B., Martín, A., Hess, S., Martínez-Torvisco, J., Suárez, E., Salazar, M., \& Ramírez, G. (2005). Análisis multidimensional de la percepción del delito ecológico. Medio Ambiente y Comportamiento Humano, 6(1), 51-70.

INEC. (29 de Septiembre de 2019). Cantón Quevedo. Obtenido de VI Censo de población y V de vivienda en 2001: https://www.ecuadorencifras.gob.ec/documentos/webinec/Bibliotecas/Fasciculos_Censal es/Fasc_Cantonales/Los_Rios/Fasciculo_Quevedo.pdf

INEC. (29 de Septiembre de 2019). Resultados del Censo 2010 de población y vivienda en el Ecuador. Obtenido de Fascículo Provincial Los Ríos: https://www.ecuadorencifras.gob.ec/wp-content/descargas/Manulateral/Resultadosprovinciales/los_rios.pdf

Meier, H. (2007). Introducción al derecho ambiental. Caracas, Venezuela: Profesor de Derecho Ambiental. UNIMET. 


\section{Subsistema de áreas naturales protegidas para enfrentar delitos ambientales contra la fauna del cantón Quevedo}

Vol. 3, núm. 3., (2019)

Karen Mercedes Barragán Monrroy; Holger Bolívar Alvarado Onofre

Mendoza, K. A. (2009). Las áreas naturales protegidas frente a la actividad hidrocarburífera. Las organizaciones ambientalistas y la gobernanza ambiental en el Ecuador: El caso del Parque Nacional Yasuní. Letras verdes, (3), 14-16.

Ministerio-del-Ambiente-del-Ecuador. (29 de Septiembre de 2019). Áreas protegidas del Ecuador socio estrategico para el desarrollo. Obtenido de http://suia.ambiente.gob.ec/documents/10179/346525/Areas+Protegidas+del+Ecuador.pd f/390b099f-6f57-4d38-bf17-cea3a138caf5

Ministerio-del-Ambiente-del-Ecuador. (29 de Septiembre de 2019). Estadísticas del Patrimonio Natural. Obtenido de Datos de bosques, ecosistemas, especies, carbono y deforestación del

Ecuador

Continental: http://suia.ambiente.gob.ec/documents/10179/346525/ESTADISTICAS+DE+PATRIMO NIO+FINAL.pdf/b36fa0a7-0a63-4484-ab3e-e5c3732c284b

Ministerio-del-Ambiente-del-Ecuador. (29 de Septiembre de 2019). Estrategia Nacional de Biodiversidad 2015-2030. Obtenido de Primera edición: http://maetransparente.ambiente.gob.ec/documentacion/WebAPs/Estrategia\%20Nacional $\%$

Ministerio-del-Ambiente-del-Ecuador. (29 de Septiembre de 2019). Informe del trafico ilegal de especies año $2014 . \quad$ Obtenido de http://suia.ambiente.gob.ec/documents/10179/346527/Informe+de+tr\%C3\%A1fico+ilega 1+2014+Final.pdf/a34c4ea9-78d0-4d0d-8425-ee97bb1a2dbb

Ministerio-del-Ambiente-del-Ecuador. (29 de Septiembre de 2019). Plan Estratégico del Sistema Nacional de Áreas Protegidas del Ecuador 2007-2016. Obtenido de Informe Final de Consultoría. Proyecto GEF: Ecuador Sistema Nacional de Áreas Protegidas (SNAPGEF):

http://maetransparente.ambiente.gob.ec/documentacion/WebAPs/PLAN\%20ESTRATEG ICO\%20DEL\%20SNAP.pdf

Ministerio-del-Ambiente-del-Ecuador. (29 de Septiembre de 2019). SUBSISTEMAS DE AREAS NATURALES PROTEGIDAS. Obtenido de http://areasprotegidas.ambiente.gob.ec/es/info-snap

Ministerio-del-Ambiente-del-Ecuador. (2019). Tratados multilaterales sobre el medio ambiente y desarrollo sostenible. Quito, Ecuador.

Moreno, D. W., Salazar, J. A., Aveiga, M. D., \& Peñaherrera, H. L. (2018). Propuesta de creación de un área protegida municipal de recreación en el sector las pozas del cantón Milagro. RECIMUNDO: Revista Científica de la Investigación y e Conocimiento, 2(2), 148-182. 


\section{Subsistema de áreas naturales protegidas para enfrentar delitos ambientales contra la fauna del cantón Quevedo}

Vol. 3, núm. 3., (2019)

Karen Mercedes Barragán Monrroy; Holger Bolívar Alvarado Onofre

Paz Salinas, M. F. (2008). De áreas naturales protegidas y participación: convergencias y divergencias en la construcción del interés público. Nueva antropología, 21(68), 51-74.

Pazmiño, M. G. (2011). La responsabilidad penal en los delitos ambientales mediante el incremento de las penas establecidas en los artículos 437 A-437 J del Código Penal. Quito, Ecuador: Trabajo de Grado - Universidad San Francisco de Quito, Colegio de Jurisprudencia.

Portilla, R. D. (2010). Los Delitos Ambientales y la Actuación Procesal de los Fiscales Especializados en Materia Ambiental. Derecho \& Sociedad, (35), 140-145.

Quevedo Pino, O. (29 de Septiembre de 2019). Ficha Ramsar del Humedal Abras de Mantequilla $\quad$ Ecuador 2008. Obtenido de http://suia.ambiente.gob.ec/documents/783967/889253/Ficha+Ramsar+Humedales+de+A bras+de+Mantequilla\%2C\%20Mapancillo\%2C\%20El+Garzal+y+San+Juan.pdf/c13c543 b-81cf-4786-b03c-bd6d32577077

Sánchez Tortosa, F., \& Shiguango Párraga, R. C. (2015). El Turismo como herramienta de Gestión de la Biodiversidad. En T. Toulkeridis, L. Andrade, M. Mejía, R. Cartay, \& L. Regalado, Memorias. Contribuciones Científicas (págs. 63-68). Manabí, Ecuador: VIII Jornadas Académicas de Turismo y Patrimonio, Compartiendo lo nuestro con el mundo.

Sepúlveda, C., Moreira, A., \& Villarroel, P. (1997). Conservación biológica fuera de las áreas silvestres protegidas. Ambiente y desarrollo, 13(2), 48-58.

Toledo, V. M. (2005). Repensar la conservación: ¿ áreas naturales protegidas o estrategia bioregional? Gaceta ecológica, (77), 67-83.

Ulloa, R., Izurieta, X., Poats, S., Bajaña, F., Viteri, X., Castillo, M., . . Ribadeneira, M. (2003). Análisis de los Procesos de Descentralización y de Delegación del Manejo de Áreas Protegidas del Sistema Nacional de Áreas Protegidas del Ecuador: el Parque Nacional Cajas y la Reserva Ecológica El Ángel. Quito, Ecuador: I Congreso del Sistema Nacional de Áreas Protegidas del Ecuador.

Vázquez Torres, S. M., Carvajal Hernández, C. I., \& Aquino Zapata, A. M. (2010). Áreas naturales protegidas. Veracruz, México.

Villalobos, I. (2000). Áreas naturales protegidas: instrumento estratégico para la conservación de la biodiversidad. Gaceta Ecológica, (54), 24-34.

Villareal, I. B. (2015). Propuesta de una red de áreas naturales protegidas para el Ecuador continental. Madrid, España: Trabajo de Grado - Universidad Complutense de Madrid.

Yánez, P., Núñez, M., Carrera, F., \& Martínez, C. (2011). Posibles efectos del cambio climático global en zonas silvestres protegidas de la zona andina de Ecuador. LA GRANJA. Revista de Ciencias de la Vida, 14(2), 24-44. 
Subsistema de áreas naturales protegidas para enfrentar delitos ambientales contra la fauna del cantón Quevedo

Vol. 3, núm. 3., (2019)

Karen Mercedes Barragán Monrroy; Holger Bolívar Alvarado Onofre

Zambrano, R. H. (2015). Breve historia y perspectivas para el futuro del Sistema Nacional de Áreas Protegidas del Ecuador (SNAP). En L. Andrade Alcívar, \& T. Toulkeridis, Memorias. Contribuciones Científicas 2015 (págs. 42-47). Manabí. Ecuador: VIII Jornadas Académicas de Turismo y Patrimonio, Compartiendo lo nuestro con el mundo. 